TRABAJOS DE PREHISTORIA

69, N. ${ }^{\circ}$ 2, julio-diciembre 2012, pp. 273-292, ISSN: 0082-5638

doi: $10.3989 /$ tp.2012.12092

\title{
Ocre y cinabrio en el registro funerario de El Argar
}

\author{
Ocher and cinnabar in the argaric funerary record
}

\author{
Juan A. López Padilla (*) \\ M. ${ }^{a}$ Paz de Miguel Ibáñez $(* *)$ \\ Matilde Arnay de la Rosa (***)
}

\section{RESUMEN}

Se analizan los casos de esqueletos con tinciones documentados en el ámbito argárico del Sudeste de la Península Ibérica. Se evalúan las diversas hipótesis planteadas hasta el momento en relación con el origen de estas coloraciones, tomando en consideración los análisis (SEM, XRD y espectroscopía RAMAN) realizados en cinco tumbas argáricas de Murcia y Alicante que han determinado la presencia de ocre y cinabrio. Sin descartar su posible uso en el teñido de tejidos, se propone su empleo en el maquillaje facial y corporal, siendo mayor el número de casos registrados sobre esqueletos de mujeres que de hombres.

\begin{abstract}
The known cases of Bronze Age Argaric stained skeletons found in the Southeast of the Iberian Peninsula, have been analysed. The various hypotheses proposed relating to the origin of these colorations have been evaluated in light of new data provided by SEM, XRD and RAMAN spectroscopic analysis carried out on five Argaric graves of Murcia and Alicante. The results have indicated the presence of ochre and cinnabar on some of the skeletons. Without discarding the possibility that both substances were used in dyeing fabrics, it is proposed that their main use was for face and body make-up, being
\end{abstract}

(*) Museo Arqueológico de Alicante (MARQ). Plaza Doctor Gómez Ulla s/n. 03013. Alicante.

Correo e.: japadi@dip-alicante.es

(**) Universidad de Alicante. Área de Prehistoria. 03690 San Vicente del Raspeig. Alicante. Correo e.: pdm@ua.es

(***) Dpto. de Prehistoria, Antropología e Historia Antigua. Facultad de Geografía e Historia, Universidad de La Laguna. Campus de Guajara s/n. $38071 \mathrm{La}$ Laguna. S/C de Tenerife. Dpto. de Química Analítica, Nutrición y Bromatología. Facultad de Química. 38071 La Laguna. S/C de Tenerife. Correos e.: matarnay@ull.es; lgalindo@ull.es

\author{
Luis Galindo Martín (***) \\ Clodoaldo Roldán García (****) \\ Sonia Murcia Mascarós (****)
} higher the number of recorded cases on female skeletons
compared to male.

Palabras clave: Edad del Bronce; Enterramientos; Colorantes; Arqueometría; Espectrografia atómica.

Key words: Bronze Age; Burials; Dyes; Archaeometry; Atomic spectrometry.

\section{INTRODUCCIÓN}

El empleo de colorantes en la prehistoria de la Península Ibérica parece remontarse considerablemente en el tiempo (Zilhão et al. 2010). Pero en comparación con los casos conocidos en el registro arqueológico, escasean aún los estudios orientados a concretar la naturaleza y composición de estas sustancias. Ello continúa suponiendo un gran obstáculo para corroborar o refutar las hipótesis hasta ahora planteadas en relación con su aprovisionamiento, procesado y utilización en época prehistórica. El panorama parece que empieza a cambiar en este sentido, y en los últimos años se viene asistiendo a un incremento importante en este tipo de analíticas (Capel et al. 2006; Briceño et al. 2009; Hunt y Hurtado 2009; Ríos y Liesau 2011). Su importancia se ha significado recientemente, al permitir retrotraer el uso del cinabrio como material colorante en el área del Levante de la Península Ibérica hasta los inicios

(****) Instituto de Ciencia de los Materiales de la Universidad de Valencia (ICMUV). Polígono "La Coma" s/n. 46980 Paterna (Valencia).

Correos e.: Clodoaldo.Roldan@uv.es; Sonia.Mascaros@uv.es Recibido: 18-X-2011; aceptado: 16-III-2012. 
del Neolítico, y documentar el procesado y almacenamiento de ocre en yacimientos de esta misma cronología (García Borja et al. 2004; García Borja et al. 2006).

Las aplicaciones a las que pudieron destinarse sustancias como los óxidos de hierro o el sulfuro de mercurio -el dibujo parietal, el maquillaje corporal, la decoración de la cerámica, la protección de cueros y el secado de pieles o la tinción de tejidos, entre otras (Briceño 2011)- explican el esporádico hallazgo en contextos domésticos de recipientes y utensilios implicados en su almacenamiento, procesado y aplicación. En la Edad del Bronce del Sureste de la Península Ibérica y territorios colindantes -ámbitos cronológico y geográfico en los que se centra este trabajo- se han documentado en San Antón, en Orihuela (Alicante), donde en su día se hallaron "sustancias colorantes con el correspondiente morterito de piedra para triturarlas" (Furgús 1937: 24) o el Cerro de El Cuchillo, en Almansa (Albacete), donde se localizó un pequeño recipiente cerámico que contenía polvo de una sustancia de color rojo intenso, todavía no analizada, interpretada como ocre (Hernández y Simón 1994: 213, lám. IV.2).

Pero es ante todo en el registro funerario donde estos colorantes -fundamentalmente rojizosse encuentran más y mejor representados. No haremos aquí un inventario exhaustivo de dicho registro, el cual sigue siendo en lo básico el ya publicado (Martínez Navarrete 1984; Delibes 2000). Nuestra atención se centrará en los esqueletos, huesos y otros restos teñidos en algunas sepulturas de la Edad del Bronce del Sureste de la Península Ibérica pertenecientes al grupo arqueológico argárico.

\section{ESQUELETOS Y HUESOS TEÑIDOS EN LAS SEPULTURAS ARGÁRICAS DEL SUDESTE PENINSULAR}

La existencia de partes esqueléticas con coloraciones anómalas en algunos de los enterramientos de la cultura de El Argar es una particularidad ya observada por los hermanos E. y L. Siret (1890: 197). En su monumental obra Las Primeras Edades del Metal en la Península Ibérica se describen con cierto detalle los casos de las tumbas 5, 129, 202, 356 y 797 del propio yacimiento de El Argar (Siret y Siret 1890: 200-201) (Fig. 1) y los de la tumba 12 de Fuente Álamo (Siret y
Siret 1890: 262; Lám. 65.12). Según sus anotaciones de campo, en El Oficio se encontraron también manchas de color rojo sobre los esqueletos de las tumbas 30, 128 y 143 (Schubart y Ulreich 1991: 215, 223 y 224).

Contemporáneamente a los Siret, Julio Furgús (1937: 24) mencionaba la existencia de esqueletos con los huesos de las manos, los pies, piernas y brazos "pintados" en el yacimiento oriolano de San Antón. El caso mejor documentado es un enterramiento femenino (Furgús 1905: 367-370, Figs. 4 y 5) cuyo esqueleto mostraba los huesos de los brazos y antebrazos "groseramente pintados" de negro y rojo, y el cráneo completamente embadurnado de negro (Furgús 1937: 56).

A lo largo del siglo XX otros yacimientos argáricos del Sudeste de la Península Ibérica fueron proporcionando esporádicamente testimonios de esqueletos con parte de sus huesos teñidos, por lo general de color rojizo (Fig. 2).

En La Bastida se menciona el caso de varias tumbas en las que se identifican coloraciones sobre los huesos o sedimentos de color rojo en contacto directo con los esqueletos (Martínez Santa-Olalla et al. 1947: 106, 108, 110). En la sepultura 9 del Cerro del Culantrillo, un enterramiento en fosa, al parecer individual, había varios restos óseos humanos coloreados de rojo (García

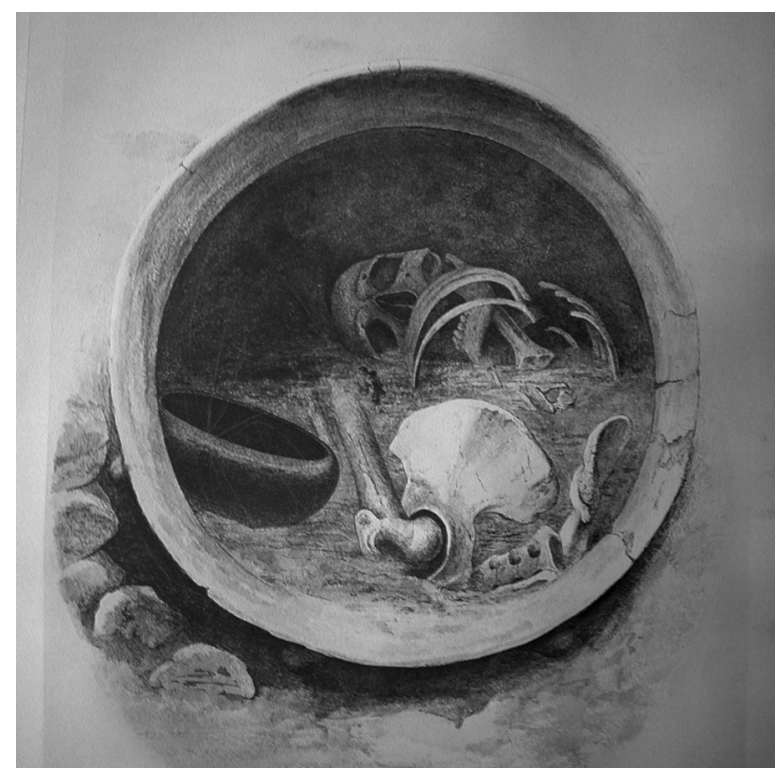

Fig. 1. Tumba 5 de El Argar (Antas, Almería), según E. y L. Siret (1890: lám. 29). 


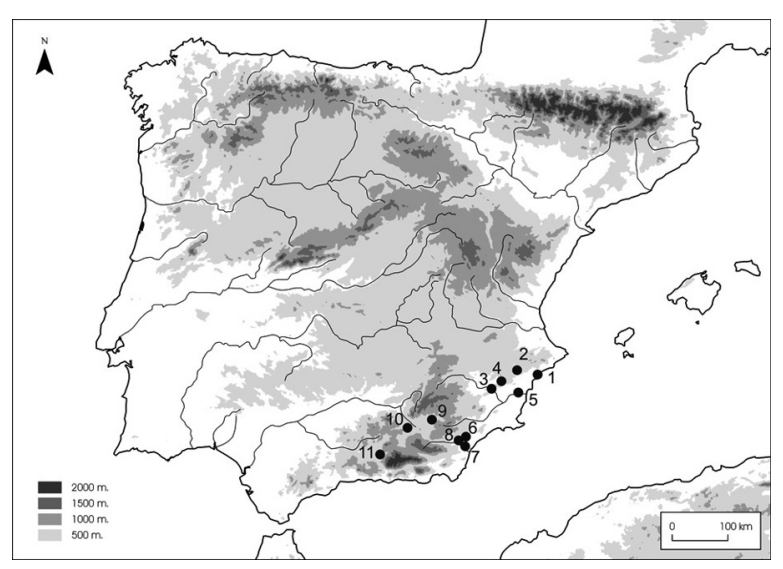

Fig. 2. Localización en la Península Ibérica de los yacimientos argáricos con referencias a esqueletos con coloraciones: 1. Illeta dels Banyets (El Campello, Alicante), 2. Tabayá (Aspe, Alicante), 3. Calle Los Tintes y Convento de las Madres Mercedarias (Lorca, Murcia), 4. La Bastida (Totana, Murcia), 5. San Antón (Orihuela, Alicante), 6. Fuente Álamo (Cuevas de Almanzora, Almería), 7. El Argar (Antas, Almería), 8. El Oficio (Cuevas de Almanzora, Almería), 9. Cerro de la Virgen (Orce, Granada), 10. Cerro del Culantrillo (Gorafe, Granada), 11. Cerro de la Encina (Monachil, Granada).

Sánchez 1963: 75). Más tarde se dieron a conocer nuevos casos en la provincia de Granada (Carrasco Rus 1979: 272), nunca detallados, pero que llegaron a analizarse mediante espectrografía. Según el gráfico publicado la muestra procedería de alguna de las sepulturas del Cerro de la Virgen (Carrasco Rus 1979: 277). Al parecer, también alguno de los enterramientos de la Cuesta del Negro presentaba coloraciones rojizas (1).

A finales del siglo $\mathrm{XX}$ se registraron nuevas sepulturas con huesos humanos teñidos en el subsuelo del casco urbano de Lorca (Martínez et al. 1996), en la tumba 2 de la Plaza de Juan Moreno, confluencia con la calle Los Tintes (Martínez y Ponce 2002b: 155) y en la tumba 12 del solar excavado bajo la antigua iglesia del Convento de las Madres Mercedarias (Martínez y Ponce 2002a: 124).

En fechas más recientes se dio a conocer el hallazgo de sustancias colorantes en las sepulturas 65,70 y 111 de Fuente Álamo a partir del análisis espectrográfico de muestras tomadas de

(1) Botella López, M. C. 1976: Antropología de las poblaciones argáricas. Tesis doctoral inédita. Universidad de Granada. Citado por Martínez Navarrete (1984: 35). su interior (Juan Tresserras 2004). Más tarde se detectaron en dos sepulturas de la Illeta dels Banyets, excavadas en las décadas de 1970 y 1980 pero que se revisaron a la luz de los datos proporcionados por excavaciones más recientes (Soler Díaz 2006). Estos estudios advirtieron la presencia de huesos con pigmentaciones de color rojo en las tumbas I y V (López Padilla et al. 2006). El último caso del que tenemos noticia es la tumba 21 del Cerro de la Encina (Aranda et al. 2008: 238).

La tabla 1 detalla la información arqueológica recopilada de todas estas sepulturas argáricas.

\section{HUESOS COLOREADOS: TEJIDOS TEÑIDOS O ESQUELETOS PINTADOS}

En las primeras apreciaciones de los hermanos Siret y de J. Furgús quedaron ya esencialmente formuladas las dos principales hipótesis que han tratado de explicar la presencia de huesos coloreados en las sepulturas prehistóricas y que desde entonces se han venido planteando de forma recurrente en la bibliografía (Martínez Navarrete 1984: 33; Delibes 2000: 227).

Para los Siret estas pigmentaciones eran el resultado de la migración a los huesos de las sustancias colorantes empleadas en la tinción de las telas, sudarios o prendas de vestir con las que estaban ataviados los difuntos en el momento de producirse su enterramiento. La tinción de partes del esqueleto no tendría un carácter intencional -o al menos no con un sentido particularmente simbólico, relacionado con el propio enterramiento- sino que se debería a las reacciones químicas ligadas al complejo proceso de putrefacción del cadáver y descomposición de su indumentaria en el interior de la sepultura. La prueba decisiva de ello sería la peculiar impronta en forma de franja localizada sobre la frente del cráneo femenino de la tumba 356 de El Argar. Esta únicamente podría deberse a la desaparición de una cinta impregnada de colorante que emularía las diademas de metal halladas en otras sepulturas (Siret y Siret 1890: 198). A ello se sumarían otros indicios, en especial las improntas de tejido sobre pellas de arcilla endurecida encontradas en la tumba 797 del mismo yacimiento, en las que podían advertirse manchas de color rojizo (Siret y Siret, 1890: 201). 


\begin{tabular}{|c|c|c|c|c|c|c|c|}
\hline Yacimiento & T. & Tipo & Ent. & Sexo/edad & Ajuar & Observaciones & Bibliografía \\
\hline El Argar & 5 & uma & 1 & $\begin{array}{l}\mathrm{H} \text { - adulto } \\
\text { joven }\end{array}$ & Hacha, puñal y vasija forma 3 & Vestigios de materia roja en el cráneo & $\begin{array}{l}\text { Siret y Siret } 1890 \text { : } 201 \text {; Jacques } 1890 \text { : } \\
478\end{array}$ \\
\hline El Argar & 129 & cista & 1 & M - anciana & $\begin{array}{l}\text { Cuchillo, punzón, vasijas forma } 5 \text { y } \\
\text { forma } 8\end{array}$ & $\begin{array}{l}\text { El cráneo presentaba claramente una } \\
\text { faja de color }\end{array}$ & $\begin{array}{l}\text { Siret y Siret 1890: lám.37; Jacques 1890: } \\
\text { 397; tab. XXVI Schubart y Ulreich 1991: } \\
\text { taf. } 10\end{array}$ \\
\hline El Argar & 202 & cista & 2 & $\begin{array}{l}\mathrm{H} \text { - adulto ( }) \\
\mathrm{M} \text { - adulta }\end{array}$ & $\begin{array}{l}\text { Punzón, vasija forma } 3 \text {, siete botones } \\
\text { de marfil y punzón de hueso }\end{array}$ & $\begin{array}{l}\text { Película de cinabrio sobre los huesos. } \\
\text { Uno de los cráneos con manchas de } \\
\text { cinabrio en el pómulo }\end{array}$ & $\begin{array}{l}\text { Siret y Siret 1890: 200; Lám. } 41 ; \text { Jacques } \\
\text { 1890: } 397 ; 480 \text {; Schubart y Ulreich 1991: } \\
\text { 90; taf. } 16\end{array}$ \\
\hline El Argar & 356 & uma & 2 & $\begin{array}{l}\mathrm{H} \text { - adulto (i) } \\
\mathrm{M} \text { - adulta }\end{array}$ & $\begin{array}{l}\text { Vasijas forma } 5 \text { y forma } 8 \text { y cuenta } \\
\text { de collar de hueso }\end{array}$ & $\begin{array}{l}\text { Banda de color rojizo sobre la frente } \\
\text { del cráneo de la mujer }\end{array}$ & $\begin{array}{l}\text { Siret y Siret 1890: 198; lám. XX. } 1 \text { y 2; } \\
\text { Jacques 1890: } 397\end{array}$ \\
\hline El Argar & 797 & cista & 2 & $\begin{array}{l}\mathrm{H} \text { - adulto } \\
\text { maduro } \\
\mathrm{M} \text { - adulta } \\
\text { madura } \\
\end{array}$ & $\begin{array}{l}\text { Cuchillo, punzón, forma } 1 \text { y vasija } \\
\text { forma } 3\end{array}$ & $\begin{array}{l}\text { Manchas de cinabrio sobre la frente } \\
\text { de la mujer. Películas de cinabrio } \\
\text { sobre improntas de tejido } \\
\text { conservadas en pellas de barro }\end{array}$ & $\begin{array}{l}\text { Jacques 1890: } 478 \text { y } 480 \text {; Schubart y } \\
\text { Ulreich } 1991: 157 \text {, taf. } 53\end{array}$ \\
\hline El Oficio & 30 & cista & 2 & $\begin{array}{l}\mathrm{H} \text { - adulto } \\
\mathrm{M} \text { - adulta (i) }\end{array}$ & $\begin{array}{l}\text { Vasijas forma } 1 \text { y forma } 5 \text { fuera de la } \\
\text { sepultura. Cuchillo y punzón de } \\
\text { metal asociado a uno de los } \\
\text { esqueletos. Brazalete y dos aretes de } \\
\text { cobre asociado al otro }\end{array}$ & $\begin{array}{l}\text { Manchas de color rojizo sobre los dos } \\
\text { esqueletos }\end{array}$ & $\begin{array}{l}\text { Schubart y Ulreich 1991: } 215 \text {; Kunter } \\
\text { 1990: } 38\end{array}$ \\
\hline El Oficio & 128 & cista (i) & 1 & $\begin{array}{l}\mathrm{H}-\text { adulto } \\
\text { maduro }\end{array}$ & $\begin{array}{l}\text { Punzón de cobre y cuentas de collar } \\
\text { de conchas marinas }\end{array}$ & $\begin{array}{l}\text { Esqueleto en una fosa revestida de } \\
\text { piedras (६) bajo una calle o zona de } \\
\text { paso. No se localizó el cráneo. } \\
\text { Huesos con manchas de color rojo. }\end{array}$ & $\begin{array}{l}\text { Schubart y Ulreich 1991: 223; Kunter } \\
\text { 1990: } 40\end{array}$ \\
\hline El Oficio & 143 & cista & 1 & $\mathrm{H}-$ anciano & $\begin{array}{l}\text { Dos vasijas forma } 5 \text {, un cuchillo y un } \\
\text { punzón de metal }\end{array}$ & Se advertian manchas de color rojo & $\begin{array}{l}\text { Schubart y Ulreich 1991: 224, taf. } 41 \text {; } \\
\text { Kunter } 1990: 41\end{array}$ \\
\hline $\begin{array}{l}\text { Fuente } \\
\text { Alamo }\end{array}$ & 12 & uma & 1 & M - acdulta (i) & $\begin{array}{l}\text { Cuchillo, punzón, pendiente de plata, } \\
\text { brazalete de aleación de cobre y } \\
\text { plata, vasij a forma } 5 \text { y vasij a } \\
\text { piriforme con asas }\end{array}$ & Contenía cinabrio & $\begin{array}{l}\text { Siret y Siret 1890: Lám. 65.12; Siret y } \\
\text { Siret 1890: 262; Schubart y Ulreich } \\
\text { 1991: 263, taf. } 115.12\end{array}$ \\
\hline $\begin{array}{l}\text { Fuente } \\
\text { Álamo }\end{array}$ & 65 & cista & 1 & $\mathrm{M}$ - adulta & $\begin{array}{l}\text { Cuchillo, punzón, brazal ete, dos } \\
\text { espirales de plata, vasijas forma } 5 \text { y } \\
\text { forma } 6\end{array}$ & $\begin{array}{l}\text { Restos de una sustancia colorante, al } \\
\text { parecer compuesta por cinabrio y } \\
\text { óxi dos de hierro, en una muestra } \\
\text { tomada del interior de la tumba }\end{array}$ & $\begin{array}{l}\text { Arteaga y Schubart 1981: } 16 . \text { Lám.8.d; } \\
\text { Kunter 2000: 267, Tab. 1; Juan } \\
\text { Tresserras 2004: } 136\end{array}$ \\
\hline $\begin{array}{l}\text { Fuente } \\
\text { Álamo }\end{array}$ & 70 & covacha & 1 & M - adulta & Cuchill o y punzón (*) & \begin{tabular}{|l} 
Restos de sulfuro de mercurio \\
(cinabrio) y oxidos de hierro \\
(hematites)
\end{tabular} & $\begin{array}{l}\text { Arteaga y Schubart 1981: 17. Lám.6.b; } \\
\text { Kunter 2000: 267, Tab. 1; Juan } \\
\text { Tresserras 2004: 137 }\end{array}$ \\
\hline $\begin{array}{l}\text { Fuente } \\
\text { Álamo }\end{array}$ & 111 & uma & 1 & $\begin{array}{l}\text { M - adulta } \\
\text { joven }\end{array}$ & $\begin{array}{l}\text { Cuchillo, tres brazaletes de bronce, } \\
\text { siete espirales, cinco aretes, } 50 \\
\text { cuentas de collar, una copa forma } 7 \text {, } \\
\text { vasija forma } 5 \text { y vasija forma } 8\end{array}$ & $\begin{array}{l}\text { Presencia de sulfuro de mercurio y } \\
\text { óxidos de hierro en una muestra } \\
\text { tomada de la zona cercana al cráneo }\end{array}$ & $\begin{array}{l}\text { Schubart 2004: } 61 \text {, abb. 2; Kunter 2004: } \\
\text { 90; Juan Tresserras. 2004: } 137\end{array}$ \\
\hline San Antón & - & cista & 1 & M - adulta (i) & $\begin{array}{l}\text { Cuchillo, punzón con mango de } \\
\text { hueso, dos pendientes en espiral de } \\
\text { plata, } 75 \text { conos de oro perforados, } \\
\text { tres conchas marinas perforadas, dos } \\
\text { discos de marfil perforados, vasija } \\
\text { forma } 4\end{array}$ & $\begin{array}{l}\text { El esqueleto tenía los huesos de los } \\
\text { brazos y antebrazos "groseramente } \\
\text { pintados" de negro y rojo, y el cráneo } \\
\text { completamente embadurnado de } \\
\text { negro }\end{array}$ & $\begin{array}{l}\text { Furgús 1905: 367-370, fig. } 4 \text { y 5; Furgús } \\
\text { 1937: } 56\end{array}$ \\
\hline La Bastida & 62 & cista & 1 & ${ }_{-}^{(\vdots)}$ adulto/a (i) & $\begin{array}{l}\text { Dos pendientes de plata, vasija forma } \\
5\end{array}$ & $\begin{array}{l}\text { Coloración rojiza del sedimento que } \\
\text { rodeaba el esqueleto, asi como "una } \\
\text { línea mury fina de tierra gris clara" } \\
\text { que parecía trazar la forma del } \\
\text { cuerpo. El cráneo y algunos huesos } \\
\text { presentaban manchas azuladas } \\
\end{array}$ & $\begin{array}{l}\text { Martínez Santa-Olalla } \text { et al. 1947: 106, } \\
108,110\end{array}$ \\
\hline $\begin{array}{l}\text { Cerro del } \\
\text { Culantrillo }\end{array}$ & 9 & fosa & 1 & $\begin{array}{l}(6) \\
- \text { adulto/a }(\dot{a})\end{array}$ & $\begin{array}{l}\text { Dos recipientes cerámicos de tamaño } \\
\text { mediano }\end{array}$ & $\begin{array}{l}\text { Coloraciones rojizas en algunos } \\
\text { huesos del esqueleto }\end{array}$ & García Sánchez 1963: 75 \\
\hline Los Tintes & 2 & fosa & 2 & \begin{tabular}{|l}
$\mathrm{H}$ - adulto \\
$\mathrm{M}$ - adulta \\
\end{tabular} & Punzón y pata de bóvido & $\begin{array}{l}\text { Trazo de color rojo sobre el cráneo } \\
\text { del varón }\end{array}$ & Martinez y Ponce 2002: 155 \\
\hline $\begin{array}{l}\text { Madres } \\
\text { Mercedarias }\end{array}$ & 12 & cista & 1 & M - adulta & $\begin{array}{l}\text { Cuchillo, punzón, dos pendientes de } \\
\text { plata, vasij as forma } 5 \text { y forma } 3\end{array}$ & $\begin{array}{l}\text { Sobre los huesos se apreció una capa } \\
\text { muy fina de sustancia de color rojizo. } \\
\text { Al levantarlos, se comprobó que se } \\
\text { extendía también bajo los huesos } \\
\end{array}$ & Martínez y Ponce $2002: 124$ \\
\hline $\begin{array}{l}\text { Cerro de la } \\
\text { Encina }\end{array}$ & 21 & fosa & 2 & $\begin{array}{l}\mathrm{H}-\text { adulto } \\
\text { joven } \\
\mathrm{M}-\text { adulta } \\
\text { joven }\end{array}$ & $\begin{array}{l}\text { H: dos pendientes de plata en espiral, } \\
\text { dos pulseras, "brazalete de arquero", } \\
\text { cuchillo de cobre con remaches de } \\
\text { plata, cuatro cuentas de collar de } \\
\text { piedra, dos cuencos de cerámica y } \\
\text { parte de una pata de bóvido. } \\
\text { M: Tres pulseras de cobre y una de } \\
\text { plata, anillo de plata, dos aretes de } \\
\text { cobre, punzón de cobre, espiral de } \\
\text { plata, cuentas de collar de piedra y de } \\
\text { cobre, copa forma } 7 \text { y un húmero de } \\
\text { bóvido } \\
(* *)\end{array}$ & $\begin{array}{l}\text { En el borde exterior de la escápula } \\
\text { izqui erda del esqueleto de la mujer se } \\
\text { advirtió la presencia de un pigmento } \\
\text { rojizo }\end{array}$ & Aranda et alii 2008: 238 \\
\hline $\begin{array}{l}\text { Illeta dels } \\
\text { Banyets }\end{array}$ & I & cista & 2 & $\begin{array}{l}\mathrm{H}-\text { adulto } \\
\text { maduro } \\
\mathrm{M}-\text { adulta } \\
\text { joven }\end{array}$ & $\begin{array}{l}\text { H: Cuchillo con aplique de marfil, } \\
\text { fragmento de brazalete de marfil o de } \\
\text { pomo y botón de marfil } \\
\text { M: Uno o dos (G) cuencos de } \\
\text { cerámica }\end{array}$ & $\begin{array}{l}\text { El esqueleto de la mujer presenta } \\
\text { coloraciones rojizas en varios huesos, } \\
\text { principalmente en las zonas } \\
\text { epi fisiarias de brazos y piernas, así } \\
\text { como en parte de la pelvis y algunas } \\
\text { costillas }\end{array}$ & López et al. 2006: 128 \\
\hline $\begin{array}{l}\text { Illeta dels } \\
\text { Banyets }\end{array}$ & $\mathrm{V}$ & Cista $(\dot{\xi})$ & 1 & M-adulta & Punzón, cuenco y pata de ovicaprino & Coloración roja en la mandíbula & López et al. 2006: 144 \\
\hline
\end{tabular}

Tabla 1. Información arqueológica sobre las tumbas (T.) argáricas de la Edad del Bronce del sudeste de la Península Ibérica recopiladas. H: Hombre; M: Mujer. Ent.: individuos enterrados.

Trab. Prehist., 69, N. ${ }^{\circ}$ 2, julio-diciembre 2012, pp. 273-292, ISSN: 0082-5638

doi: $10.3989 /$ tp.2012.12092 
La segunda hipótesis defendía que la impregnación de los huesos sería resultado principalmente de un tratamiento post-mortem. Colorear parcial o completamente el esqueleto sería un efecto buscado intencionalmente. Furgús (1937: 55) se convirtió en un acérrimo defensor de esta hipótesis, asumiendo sin ambages que los cuerpos debían haber sido descarnados cuando no previamente incinerados para ser después coloreados antes de su depósito en la tumba.

Desde la nota redactada por E. Siret (1905) en la que rebatía con diversos argumentos las hipótesis de Furgús respecto al origen de la coloración de los esqueletos de San Antón (entre otras cuestiones de mayor calado, como el reconocimiento mismo de la existencia de un asentamiento y su contemporaneidad con las tumbas excavadas) la controversia ha continuado hasta la actualidad. En los últimos años hipótesis alternativas han tratado de explicar de forma más completa este particular aspecto del registro funerario argárico. Una de ellas propone que se trate de rudimentarias prácticas de embalsamamiento (Delibes 2000). Pero el incremento y mejora sustancial de la documentación apenas se ha visto acompañado de análisis físico-químicos encaminados a determinar la naturaleza de la materia o materias que las provocaron.

Los primeros en acudir a medios técnicos para tratar de dilucidar esta cuestión fueron los propios hermanos Siret, quienes observaron mediante microscopio las improntas con pigmentaciones rojizas localizadas en la tumba 797 de El Argar, e identificaron con precisión la presencia de cinabrio en las tumbas 202 de El Argar y 12 de Fuente Álamo (Siret y Siret 1890: 200; 226). Sin embargo, hasta finales de la década de 1970 no se contó con los primeros análisis físico-químicos. En esas fechas J. Carrasco Rus (1979: 272) daba a conocer parcialmente los resultados de un estudio de varias muestras - de cuya naturaleza no se dieron detalles - tomadas en sepulturas argáricas granadinas. Al menos una de ellas provenía del Cerro de la Virgen, según la leyenda del gráfico publicado. El análisis, realizado por el método de difracción de rayos $\mathrm{X}$, mostraba la presencia de cinabrio o sulfuro de mercurio, junto con la jarosita y el cuarzo. En opinión del autor, el cinabrio y la jarosita habrían sido empleados como colorantes textiles, y el cuarzo como desgrasante y elemento catalizador en el proceso de tinción del tejido. La descomposición de la tela durante la putrefacción del cadáver habría terminado por fijar a la superficie de los huesos que estaban en contacto con ella las sustancias utilizadas en su teñido. Así pues, a su juicio los datos vendrían a corroborar punto por punto las hipótesis de los Siret.

Con posterioridad se han venido conociendo otros estudios de muestras halladas en yacimientos calcolíticos de la península: la cueva del Cerro de Juan Barbero (Tielmes, Madrid) (Martínez Navarrete 1984: 31; Rovira y Sanz 1984: 99102), el Dolmen de Alberite (Villamartín, Cádiz) (Domínguez-Bella y Morata-Céspedes 1995: 140), La Velilla (Osorno, Palencia) (Martín Gil et al. 1994; Delibes, 2000), La Pijotilla y el Dolmen de Montelirio (Hunt y Hurtado 2009), las cuevas sepulcrales 1, 3 y 5 del valle de las Higueras (Huecas, Toledo) (Bueno et al. 2005), La Salmedina (Madrid) (Berzosa y Flores 2005) o los recientemente publicados referidos a los contextos funerarios madrileños de Humanejos, Camino de las Yeseras, Cuesta de la Reina o La Magdalena (Ríos y Liesau 2011: 367, Tab. 3) en los que análisis más o menos detalladamente publicados han identificado ocres de diverso origen y también cinabrio como material colorante vinculado a huesos de esqueletos, piezas de ajuar o a espacios de carácter funerario.

Sin embargo, hasta los análisis llevados a cabo por J. Juan Tresserras (2004) en el marco del estudio de la necrópolis de Fuente Álamo (Schubart et al. 2004) no se ha contado con nuevos datos a este respecto referidos al grupo argárico. Lamentablemente, no se publican los gráficos de las espectrografías, que es de suponer se detallarán en la monografía que se prepara desde hace tiempo sobre las sepulturas del yacimiento (Pingel et al. 2003: 196). Los datos relevantes para nuestro estudio provienen de tres tumbas. En la muestra 7 , correspondiente a sedimento oscuro procedente del interior de la tumba 65 , aparecieron restos de una sustancia colorante sobre uno de los elementos líticos contenido en la fracción de gravas, al parecer compuesta por cinabrio y óxidos de hierro. En la muestra 12, tomada en la tumba 70 , se reconocieron restos de sulfuro de mercurio (cinabrio) y también de óxidos de hierro (hematites). Finalmente, en la muestra 13, tomada en la zona cercana al cráneo de la mujer enterrada en la tumba 111, se identificó también la presencia de sulfuro de mercurio y óxidos de hierro (Juan Tresserras 2004: 136). 
Así las cosas, resultaba altamente interesante, a nuestro parecer, incrementar en la medida de lo posible la colección de datos disponible con vistas a confrontar de nuevo las dos principales hipótesis relacionadas con la presencia de tinciones rojizas en los esqueletos argáricos.

\section{ANÁLISIS DE MUESTRAS DE LA ILLETA DELS BANYETS, TABAYÁ, CALLE DE LOS TINTES Y CONVENTO DE LAS MADRES MERCEDARIAS}

Solo en tres de los yacimientos conocidos en el área argárica más oriental se ha dado noticia de restos óseos humanos con tinciones o coloraciones rojizas: la Illeta dels Banyets, en El Campello (Alicante), el Tabayá, en Aspe (Alicante) y el asentamiento que se localiza bajo el casco urbano de Lorca (Murcia).

Las muestras de estos yacimientos se analizaron en el Servicio de Microscopía de los Servicios Generales de Apoyo a la Investigación de la Universidad de La Laguna, en Tenerife, mediante un Microscopio electrónico de barrido (SEM, Scanning electron microscope) JEOL JSM-6300 con microanálisis de energías dispersivas de rayos-X (EDS) D6699-ATW (Oxford Instruments, $U K)$. Las muestras destinadas al SEM fueron depositadas sobre portamuestras metálicos y recubiertas con una capa conductora de carbono, procediendo, a continuación, a registrar los espectros $E D S$ correspondientes al microanálisis elemental de las muestras con restos de pigmentos.

A continuación se detalla el contexto arqueológico y la procedencia de cada una de las muestras analizadas, así como los resultados de los espectros realizados.

\subsection{Illeta dels Banyets}

\section{Tumba I}

Es un enterramiento doble en cista de mampostería excavada en 1974, del que se conservan referencias fotográficas. A partir de éstas y de los croquis de excavación sabemos que en la zona oriental del interior de la cista aparecieron los restos óseos, en perfecta conexión anatómica, de un varón adulto maduro de unos 50 años de edad, recostado sobre su lado izquierdo. En el extremo suroccidental de la tumba se localizaba además un paquete óseo perteneciente al esqueleto de una mujer adulta de aproximadamente 30 años de edad (López Padilla et al. 2006: 126-130, Figs. 53-54) (Fig. 3).

Estos últimos son los que aquí nos interesan. El esqueleto de la mujer -individuo 1- sufrió una remoción dentro de la sepultura para que fuera depositado el cadáver del hombre -individuo 2-, lo que se evidencia por la pérdida de conexiones anatómicas de la mayoría de sus huesos. La extracción del paquete óseo junto con la matriz terrosa que lo contenía, nos permitió comprobar posteriormente que la columna vertebral sí se hallaba en conexión anatómica, lo que nos induce a descartar la posibilidad de un depósito secundario - esto es, el traslado de los restos desde otra sepultura-.

Para la datación por radiocarbono del individuo 1 se empleó parte del extremo distal de la

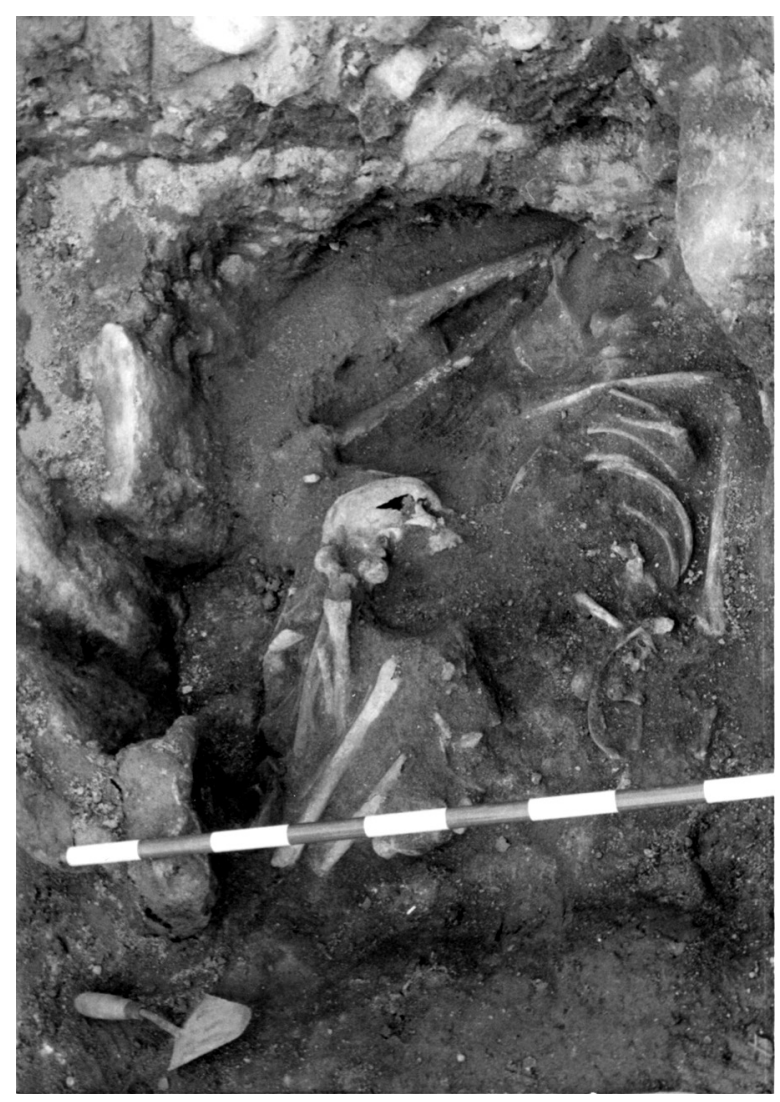

Fig. 3. Tumba 1 de la Illeta dels Banyets (El Campello, Alicante): esqueleto del individuo femenino. El Argar, Edad del Bronce. Foto: Archivo Gráfico del Museo Arqueológico de Alicante (MARQ.). 
tibia izquierda, y para la del individuo 2 una muestra de diáfisis de fémur, obteniéndose los siguientes resultados: individuo 1 (Beta 188925): $3410 \pm 60$ BP $-1865-1625$ cal BC $(1 \sigma) / 1884-$ 1536 cal BC $(2 \sigma)$-/individuo 2 (Beta 188926): $3470 \pm 50$ BP $-1880-1740$ cal BC $(1 \sigma) / 1923-$ 1667 cal BC $(2 \sigma)(2)$.

El estudio antropológico realizado ha revelado diversas patologías en el esqueleto de la mujer: varias afecciones bucales, artrosis cervical y la fractura de una costilla. Algunos de los huesos presentaban coloraciones rojizas, muy difusas, localizadas al menos en el calcáneo derecho, en los metatarsianos, ambos fémures y tibias, en la escápula derecha, sacro, húmeros, cúbitos, en alguna de las costillas y ligeramente en la hemipelvis izquierda. También se apreciaban escasos signos de contacto con el fuego en la cabeza de ambos fémures (López Padilla et al. 2006: 128).

Para el análisis espectrográfico se seleccionó una muestra (ILLETA-1974-439) del cúbito derecho, cercana a la epífisis distal, en la que podían apreciarse claramente varias zonas con pigmentación de color rojizo.

\section{Tumba V}

Estaba muy alterada por la cimentación de estructuras de época ibérica superpuestas estratigráficamente. En varias fotografías se aprecia la existencia de una posible cista rectangular de mampostería que tal vez habría aprovechado parte de un muro como una de sus paredes (López Padilla et al. 2006: 144, Fig. 71). Los huesos se hallaron desordenados y muy desplazados unos de otros. El cráneo yacía en un extremo mientras que buena parte del esqueleto postcraneal -aparentemente los huesos de las piernas- conformaban una especie de paquete irregular justo en el opuesto. Un cúbito aparecía igualmente desplazado.

El esqueleto pertenecía a una mujer adulta madura, de aproximadamente $1,62 \mathrm{~m}$ de talla, que entre otras patologías presentaba artrosis lumbar, así como también artrosis en la rótula derecha y en el primer metacarpiano y faceta de acuclillamiento en las tibias (López Padilla et al.

(2) La calibración de las fechas se ha realizado con la versión on-line del programa OxCal 4.1 (Bronk Ramsey 2009), empleando la curva IntCa109 (Reimer et al. 2009).
2006: 145, Fig. 72). El estudio osteológico reveló la presencia de unas pigmentaciones de color rojo en la parte izquierda de la mandíbula, de la que se extrajeron algunas muestras para su análisis (ILLETA-82-1966).

Las espectrografías realizadas sobre las muestras enviadas tanto de la Tumba I como de la Tumba $\mathrm{V}$ indicaron la presencia de diversos elementos químicos: oxígeno, sodio, magnesio, aluminio, silicio, fósforo, cloro, potasio, calcio, hierro y carbono (este último proveniente del recubrimiento grafítico). Al focalizar las zonas de la mancha rojiza se incrementó notablemente la señal del hierro, lo que demuestra que la sustancia rojo-anaranjada es un óxido férrico, descartándose la presencia de mercurio, plomo o cadmio, salvo que existan a nivel de trazas o ultratrazas que en cualquier caso nunca explicaría la presencia de manchas (Fig. 4).

\subsection{Tabayá}

Antes de que se realizaran excavaciones arqueológicas sistemáticas en este yacimiento ya se tenía noticia de la existencia de sepulturas que, a juzgar por sus ajuares, cabía adscribir al grupo

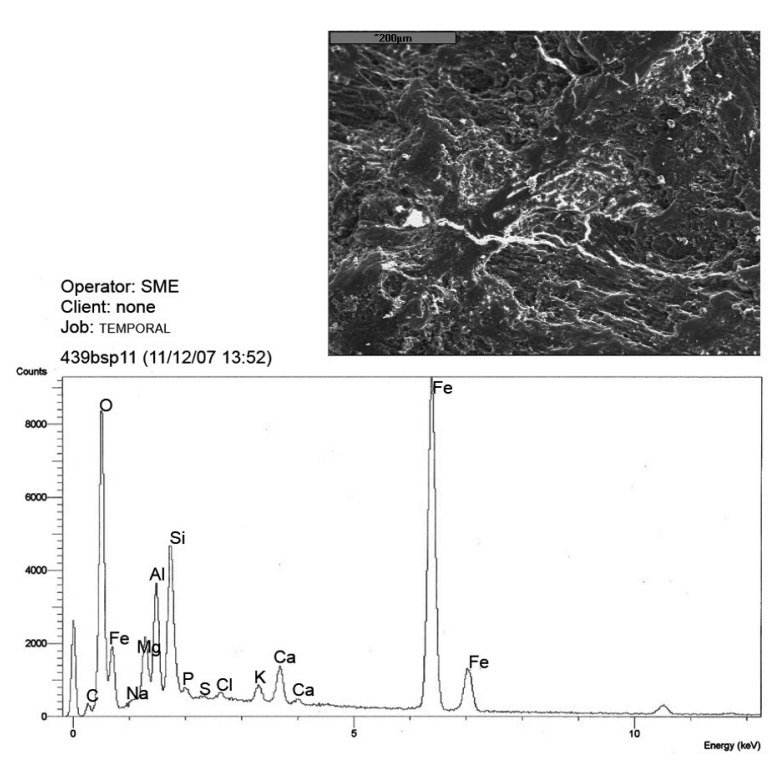

Fig. 4. Espectro $S E M-E D S$ de la muestra ILLETA-1974-439: cúbito derecho con pigmentación rojiza (un óxido férrico) del esqueleto del individuo femenino de la tumba 1 de la Illeta dels Banyets (El Campello, Alicante). 
argárico (Navarro Mederos 1982), algo que ha sido confirmado completamente con posterioridad (Hernández Pérez 1990; Hernández y López 2010). Una de las sepulturas de las que se tenía noticia, y que actualmente se halla expuesta en el Museo Arqueológico Municipal de Novelda, era un enterramiento femenino en urna (Jover y López 1997: 56). Del esqueleto sólo se conserva actualmente el cráneo, parcialmente reconstruido, que pudo ser analizado.

Consideramos que perteneció, muy probablemente, a una mujer: frente recta, órbitas oculares afiladas, apófisis mastoides gráciles, ausencia de realce nucal, además de la gracilidad mandibular, con la sínfisis mentoniana redondeada. La edad aproximada se ha determinado a partir de la total eclosión de los terceros molares inferiores. Todos los dientes conservados muestran desgaste oclusal. Las suturas craneales no presentan evidencias de sinostosis. Por tanto, consideramos que se trata de un individuo fallecido a edad adulta (30-40 años) (Buikstra y Ubelaker 1994: 16-38).

A pesar de la escasa representación esquelética y de la deficiente conservación, se han identificado algunas patologías de escasa entidad, tales como presencia de sarro y signos de enfermedad periodontal. Hay caries en la cara distal de 17, a nivel del cuello, y también en las caras oclusales de 37 y 48. En el cóndilo mandibular izquierdo se identifica un ligero reborde osteofítico relacionado con una artrosis temporo-mandibular. Dentro de las variaciones epigenéticas se documentan varios huesos wormianos en la sutura lambdoidea.

En diversas partes del cráneo se apreciaban claramente coloraciones rojizas, principalmente en pequeñas superficies del frontal, el cigomático izquierdo (también en la cara interna), en el temporal izquierdo, y en la rama ascendente izquierda de la mandíbula.

Se seleccionaron para el análisis mediante $S E M-E D S$ dos muestras: la primera (TA-1) de la parte inferior del arco zigomático, en su zona de unión con la parte interna del maxilar izquierdo y la segunda (TA-2) de la mandíbula.

Ninguna ha ofrecido resultados positivos en cuanto a la presencia de óxidos férricos o sulfuros de mercurio que expliquen las coloraciones rojizas observadas. Todos los espectros muestran una composición básicamente de fosfato cálcico con excepción del fragmento $1 \mathrm{C}$ de la muestra TA-1, en la que se advierten con nitidez silico-aluminatos.

Todo ello nos lleva a atribuir las coloraciones rojizas observadas en este cráneo a procesos de origen orgánico no determinados que también podrían explicarlas, como el crecimiento de hongos o la acción de raíces de plantas (Fig. 5).

\subsection{Lorca. Calle Los Tintes}

\section{Tumba 2}

En este enterramiento en fosa se depositaron dos individuos con las cabezas dispuestas al Suroeste y los pies al Nordeste. Según la descripción de sus excavadores, una vez abierto un agujero de forma aproximadamente rectangular en el suelo, se introdujo el cadáver de una mujer de entre 35 y 40 años de edad, en posición encogida apoyado sobre su costado izquierdo y mirando al Noroeste. Una segunda inhumación requirió el vaciado de la mayor parte de la fosa, moviendo los huesos del tercio superior del esqueleto de la mujer. Encima de éste se depositó el cadáver de un hombre de entre 35 y 45 años de edad, tam-

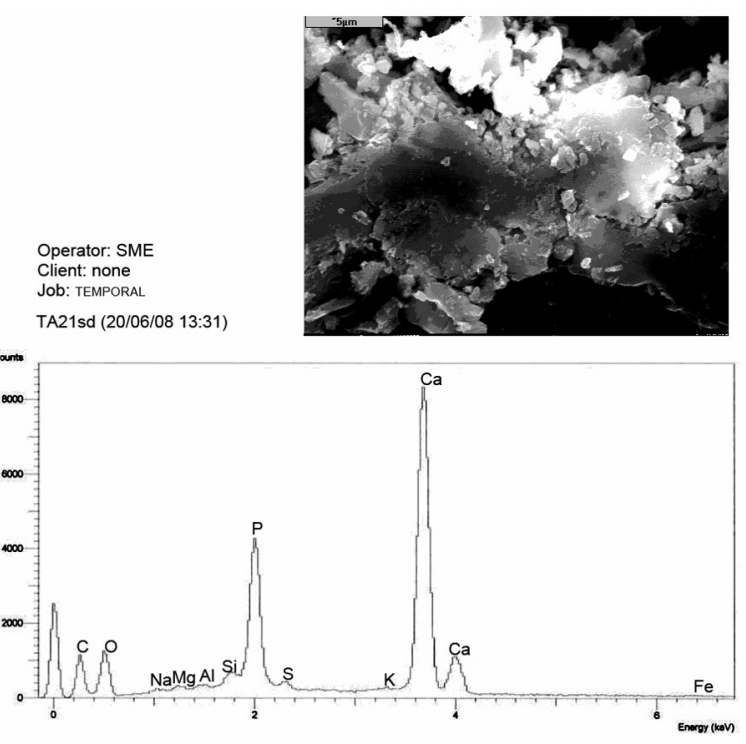

Fig. 5. Espectro SEM-EDS de la muestra TA-2: mandíbula de individuo adulto femenino procedente, posiblemente, de una sepultura en urna destruida del Tabayá (Aspe, Alicante). Los resultados no explican las coloraciones rojizas observadas. 
bién flexionado sobre su costado izquierdo y mirando al Noroeste. Al momento de la exhumación, se advirtió en el cráneo del hombre un trazo rojo que, en opinión de sus excavadores, parecía pintado con pincel.

De cada uno de los esqueletos de esta tumba se obtuvo una datación radiocarbónica: el hombre (OxA-7667): $3560 \pm 35-1959-1785$ cal ANE (1 $\sigma) / 2021-1773$ cal ANE $(2 \sigma)$ y la mujer (OxA7668): $3690 \pm 40-2140-2026$ cal ANE $(1 \sigma) /$ 2199-1960 cal ANE $(2 \sigma)(3)$ (Martínez y Ponce 2002b: 155).

Para el análisis mediante $S E M-E D S$ se seleccionó la muestra LT-27/22, un fragmento del hueso occipital del cráneo masculino, con pigmentaciones de color rojizo. Es una porción de aproximadamente $5 \mathrm{~mm}$ de espesor que conserva parte de la zona central de la sutura lambdoidea, abierta, con los dientes muy marcados, lo que resulta habitual en personas jóvenes. Sobre el fragmento se apreciaba una banda de color rojizo de $25,5 \mathrm{~mm}$ de lado mayor por $10,1 \mathrm{~mm}$ del menor.

Los resultados denotaban la presencia de sulfatos $(\mathrm{S})$, silico-aluminatos $(\mathrm{Si}, \mathrm{Al})$ y óxido de hierro ( $\mathrm{Fe}$ ) en contenido abundante, lo que permite establecer que la sustancia rojiza fijada a la superficie ósea es un óxido férrico (Fig. 6).

\subsection{Lorca. Convento de las Madres Mercedarias}

\section{Enterramiento 12}

Enterramiento en cista de mampostería, de planta aproximadamente rectangular, construida en el interior de una estructura de tendencia semicircular, interpretada como almacén. La cista, parcialmente afectada por un pozo ciego de época medieval en su parte noroccidental, conservaba más de un metro de alzado en el lado Suroeste, con unas dimensiones de aproximadamente $1,40 \mathrm{~m}$ de largo y $0,96 \mathrm{~m}$ de anchura, y una orientación Noreste-Suroeste. Algunos de los bloques pertenecientes a las paredes de la cista habían caído en el interior afectando al esqueleto, sobre cuyos huesos se apreció una capa muy fina

(3) Calibración realizada con la versión on-line del programa OxCal 4.1 (Bronk Ramsey, 2009), empleando la curva IntCal09 (Reimer et al., 2009).

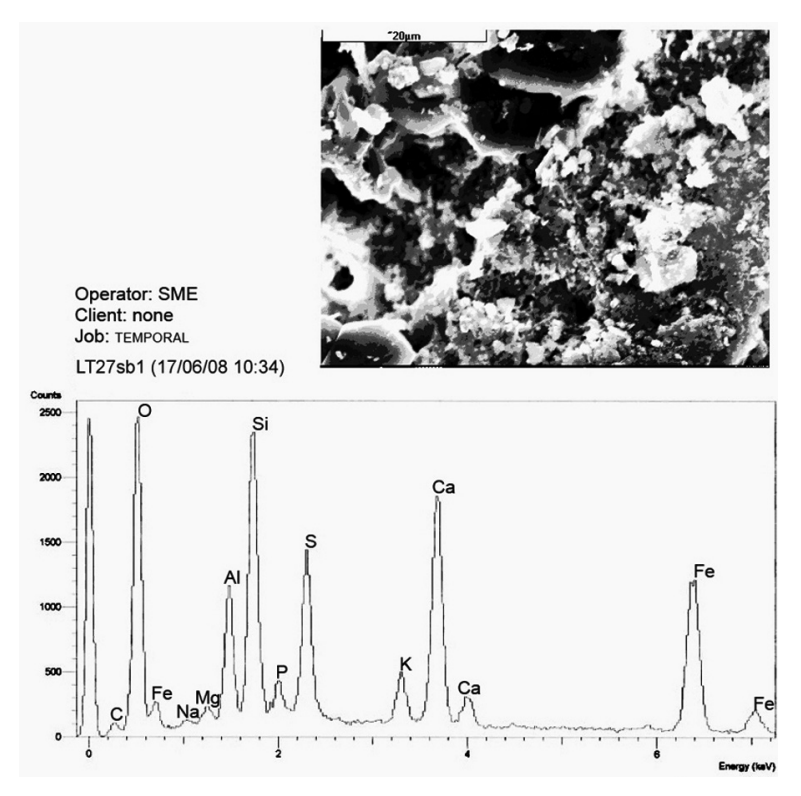

Fig. 6. Espectro SEM-EDS de la muestra LT-27/22: porción de hueso occipital con pigmentaciones rojizas (un óxido férrico) del individuo masculino del enterramiento doble de la tumba 2 de la calle Los Tintes (Lorca, Murcia).

de una sustancia de color rojizo. Al levantar los restos óseos se comprobó que ésta se extendía también por debajo de ellos. Al levantar el cráneo se localizaron restos de madera que hacen pensar en la colocación de algún elemento de este material bajo la cabeza (Fig. 7).

El esqueleto, perteneciente a una mujer adulta, estaba depositado en decúbito supino con los brazos flexionados y las manos sobre la pelvis. Las piernas, también flexionadas, aparecen en posición muy forzada, con las plantas de los pies enfrentadas próximas al sacro. La cabeza está orientada al Noreste y mirando hacia arriba. Al parecer el enterramiento pertenece a la fase más antigua de la ocupación argárica del yacimiento, en torno a 2000 cal ANE (Martínez y Ponce 2002a: 124-126, Fig. 21).

En el momento de ser analizado el esqueleto se encontraba muy parcialmente conservado, con restos muy fragmentados y alterados por tafonomía, en especial el cráneo. El esqueleto postcraneal resulta relativamente grácil, aunque también está muy alterado. La inspección de los restos permitió identificar huesos de dos individuos diferentes. Un primer conjunto muestra una clara robustez que alcanza hasta los 9,4-10,6 mm de 


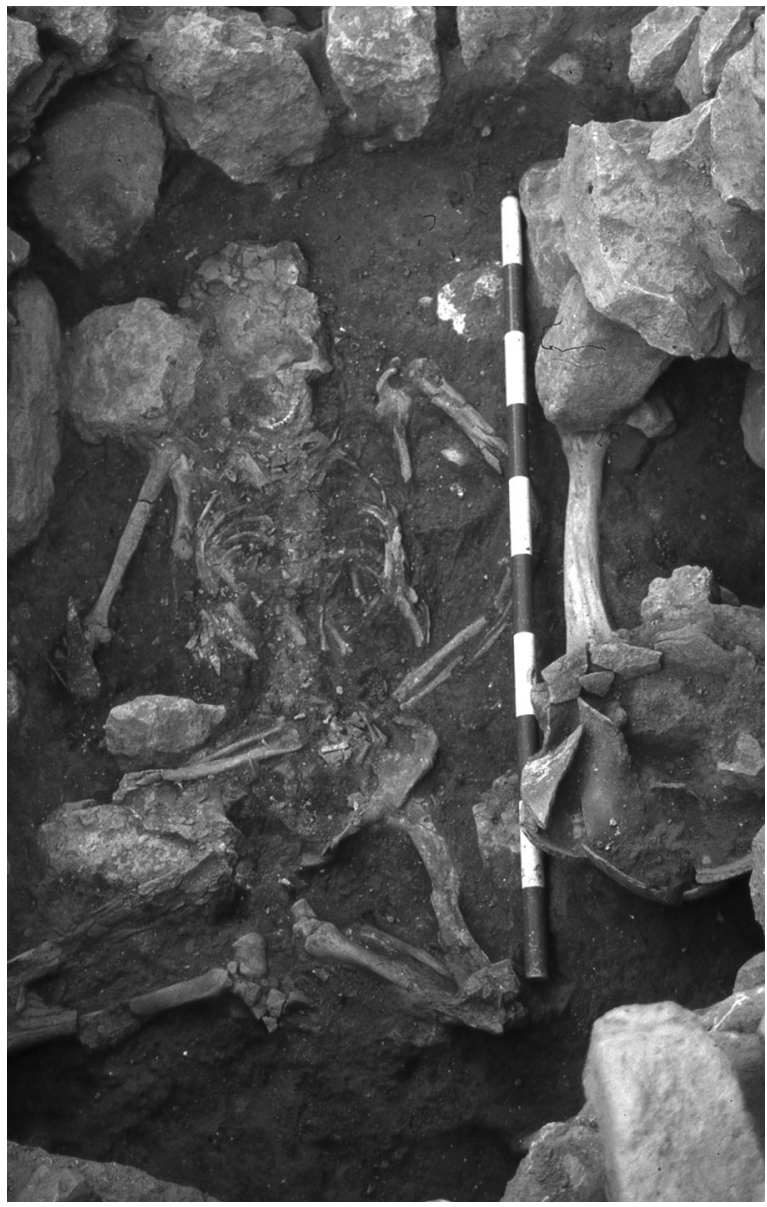

Fig. 7. Tumba 12 del Convento de las Madres Mercedarias (Lorca, Murcia): esqueleto del individuo adulto femenino. Fase más antigua de la ocupación argárica, Edad del Bronce. Foto: Archivo Gráfico del Museo Arqueológico Municipal de Lorca.

grosor en el parietal, y que también se observa en restos posiblemente de occipital y frontal. A pesar de ello, y a juzgar por la presencia de órbitas afiladas y glabela poco marcada, debieron pertenecer a una mujer en la que se produjo un engrosamiento del cráneo. La deficiente conservación de los huesos no permite hacer valoraciones sobre la extensión ni la causa de esta alteración.

En el segundo conjunto el espesor craneal es inferior a $5 \mathrm{~mm}$ (parietal: $4,8 \mathrm{~mm}$ ) y las suturas están bien marcadas y abiertas. Corresponde por tanto a un individuo juvenil o adulto joven. Los restos conservados de este segundo individuo son tan escasos que no debemos descartar que llegaran a la sepultura de manera accidental, quizás procedentes de una sepultura previa destruida, o entre la tierra que cubrió el esqueleto.

Se comprobó la presencia de manchas rojizas en una falange de la mano, en un pequeño fragmento de hueso largo no determinado y sobre una porción de costilla del esqueleto de la mujer. Este último fragmento fue seleccionado para su análisis químico elemental por la técnica SEM (muestra MM-12). Los resultados del espectro realizado sobre las partículas de la mancha rojiza permitieron reconocer inmediatamente compuestos mercuriales muy abundantes, así como un bajo contenido en fosfatos y silicatos. Ello confirma la presencia de bermellón o cinabrio y su identificación como la sustancia colorante que impregnaba los huesos de este esqueleto y también el sedimento que los rodeaba en el interior de la sepultura (Fig. 8).

Recapitulando, de las 6 muestras analizadas, en 3 -tumbas I y V de la Illeta dels Banyets y tumba 2 de la Calle de Los Tintes- se ha reconocido óxido de hierro como material colorante. En otras 2 -inhumación en urna del Tabayá- no se ha podido detectar ningún elemento ni compuesto químico que explique las coloraciones rojizas. Finalmente, solo en una -tumba 12 del Convento

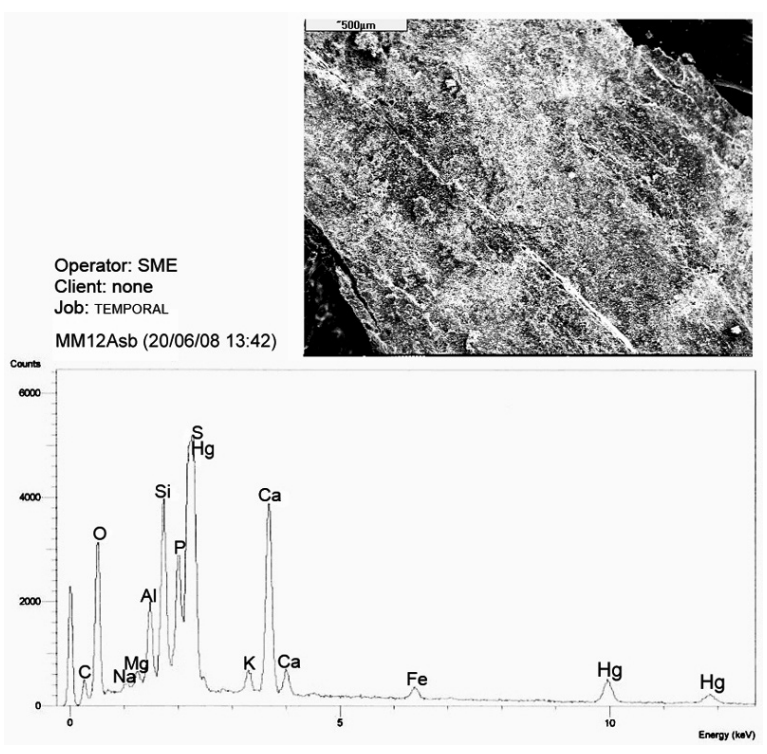

Fig. 8. Espectro SEM-EDS de la muestra MM12: porción de costilla del individuo adulto de la tumba 12 del Convento de las Madres Mercedarias (Lorca, Murcia). El cinabrio se identifica como el colorante que impregnaba los huesos de este esqueleto y el sedimento. 
de Madres Mercedarias, en Lorca- el análisis ha confirmado la presencia de cinabrio.

El origen antrópico del sulfuro de mercurio detectado en esta última sepultura resulta incuestionable, tanto si fue aplicado o espolvoreado directamente sobre el cadáver o el esqueleto o si se transfirió a la superficie de los huesos desde una mortaja o desde vestidos teñidos de rojo. Algo más difícil es precisar si el óxido de hierro detectado en las otras tres tumbas pudiera ser igualmente intencional, ya que a diferencia del cinabrio el contenido más o menos abundante de hierro en un amplio abanico de los sustratos geológicos del sur de la Península Ibérica impide descartar a priori que su depósito sobre los huesos respondiera a causas de origen meramente sedimentario.

La escasez de análisis sedimentológicos sobre muestras del interior de las tumbas es un obstáculo evidente para dilucidar esta cuestión. No obstante ciertos indicios observados en la tumba I de la Illeta dels Banyets permitían sospechar fundadamente que el óxido férrico adherido a parte de los huesos del esqueleto femenino había sido aportado con carácter intencional al enterramiento. Solo así podía explicarse que los huesos del hombre, contenidos en la misma matriz terrosa que la mujer, carecieran de coloraciones rojizas.

Para corroborar esta hipótesis se procedió a analizar en el Instituto de Ciencia de los Materiales de la Universidad de Valencia (ICMUV) una nueva muestra ósea extraída del cúbito izquierdo de la mujer y una muestra del sedimento de la tumba recogido durante la limpieza de los esqueletos. Primero se analizó la muestra sedimentaria mediante difracción de Rayos-X (XRD) y posteriormente se realizó un análisis mediante microscopía electrónica de barrido (ESEM-EDX) y espectroscopía RAMAN tanto a la muestra sedimentaria como a porciones coloreadas y no coloreadas del hueso. Para ello se utilizó, respectivamente, un microscopio electrónico de barrido ambiental Philips XL-30 ESEM con microanálisis, un difractómetro BRUKER AXS D5005 cubriendo un intervalo angular $2 \theta$ entre $2^{\circ}$ y $70^{\circ}$ y un espectrómetro Raman Horiba Jobin Yvon modelo iHR320 provisto de detector CCD con refrigeración peltier, fibra óptica y cabezal de enfoque.

El análisis $X R D$ de la muestra sedimentaria concluyó que las fases minerales identificadas correspondían a calcita y cuarzo, como elementos integrantes básicos de la matriz terrosa que envolvía los huesos de la tumba I.

A continuación se analizó mediante microscopía electrónica de barrido ambiental ESEM-EDX las muestras proporcionadas sin metalizarlas. Se seleccionaron puntos con coloración roja y zonas sin coloración para identificar y discriminar la composición de la materia colorante con respecto al material óseo. De la comparación de ambos espectros (Fig. 9) se deduce una mayor intensidad de los picos de $\mathrm{Mg}, \mathrm{Al}, \mathrm{Si}, \mathrm{K}$ y Fe en la materia colorante dispuesta sobre la superficie ósea, compatible con sustancias arcillosas ricas en óxidos de hierro y aluminosilicatos. Por el contrario, el espectro del sedimento revela compuestos de calcio y alumino-silicatos con una baja intensidad de la señal de fluorescencia asociada a óxidos de hierro (Fig. 10).

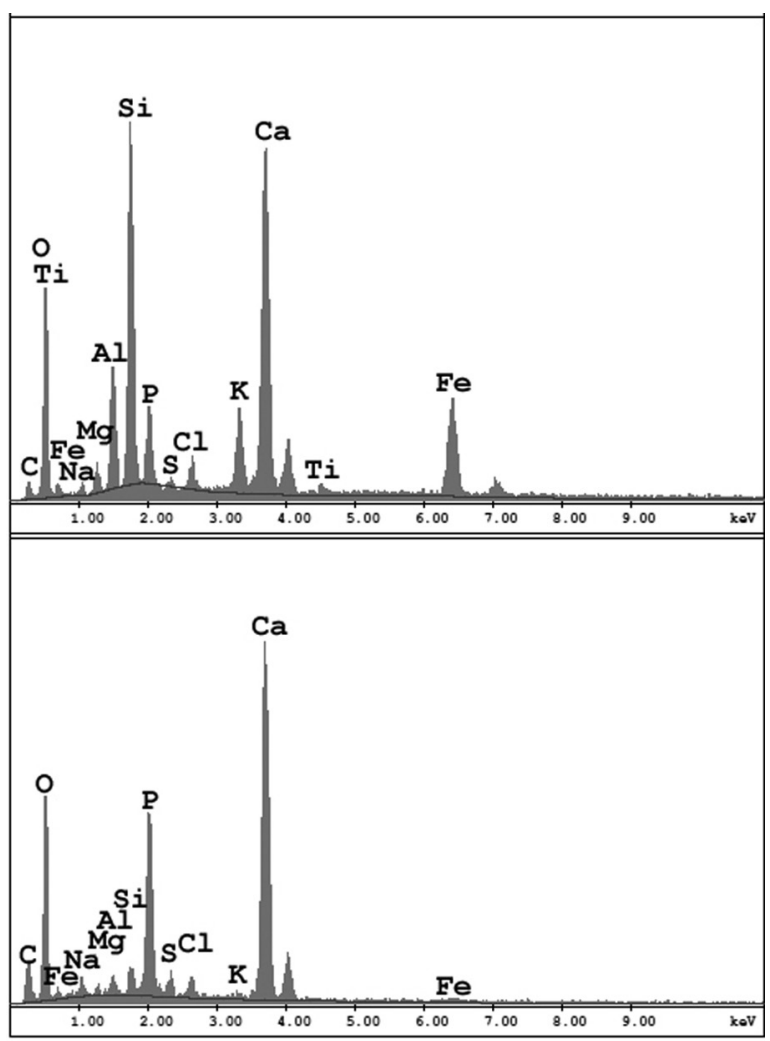

Fig. 9. Tumba 1 de la Illeta dels Banyets (El Campello, Alicante). Espectros ESEM-EDS de una muestra del cúbito izquierdo con pigmentación rojiza (óxidos férricos, arriba) y sin ella (abajo) del esqueleto del individuo femenino. 


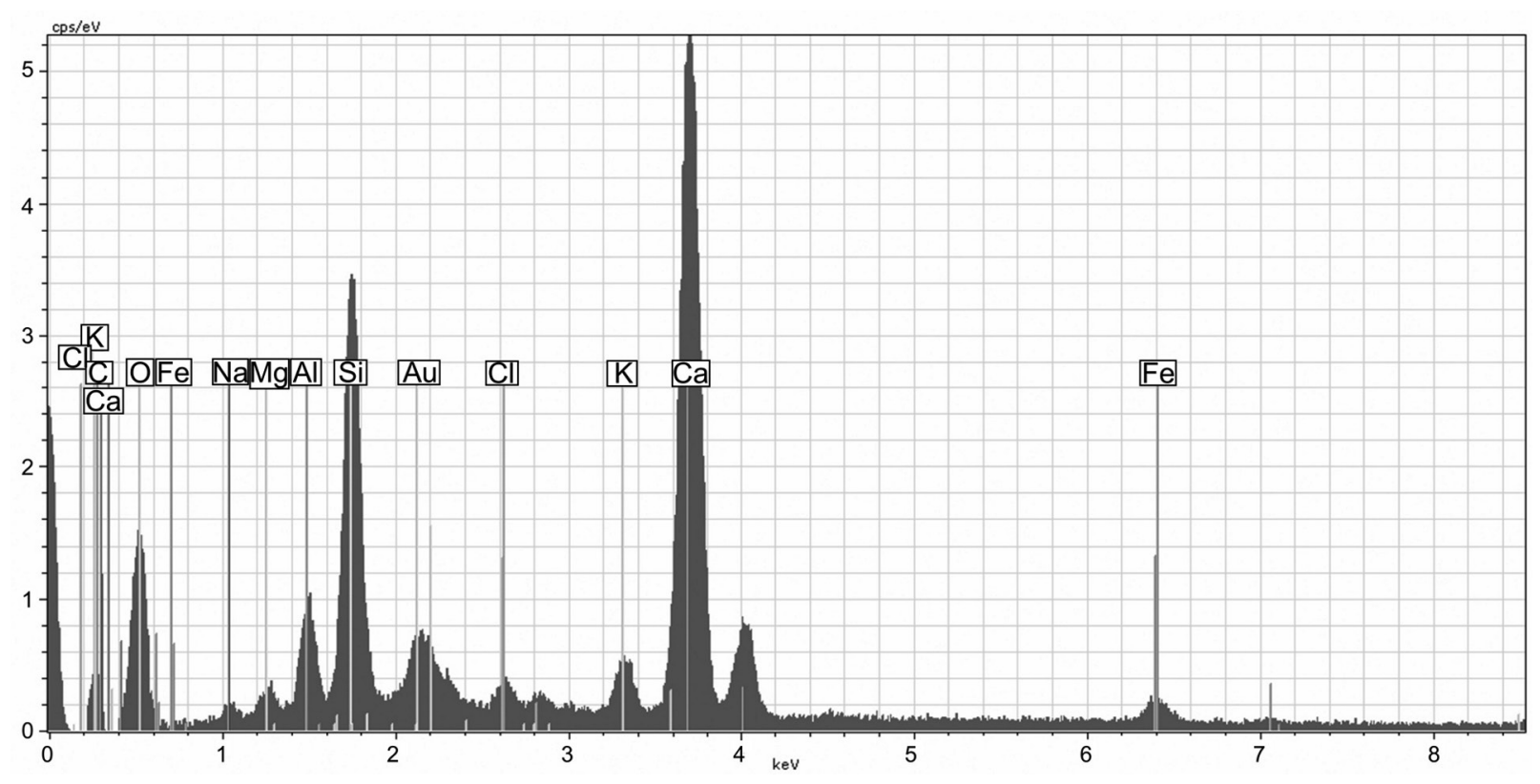

Fig. 10. Tumba 1 de la Illeta dels Banyets (El Campello, Alicante). Espectro ESEM-EDS de una muestra del sedimento recogido durante la limpieza del esqueleto del individuo femenino. Faltan los óxidos de hierro y aluminosilicatos.

Por último, se realizaron numerosas medidas de espectroscopia Raman en diferentes zonas del hueso, en particular donde la coloración roja era más intensa y donde no se observaban coloraciones. La figura 11 muestra los espectros correspondientes a las zonas citadas que son representativas del pigmento, del soporte óseo y del sedimento. Las condiciones de medida han sido las mismas en todos los casos: láser $785 \mathrm{~nm}$, apertura $100 \mu \mathrm{m}$, gratting 600 , tiempo por espectro $120 \mathrm{~s}, 25$ espectros acumulados, objetivo de larga distancia $\times 100$ y potencia láser sobre la muestra $13 \mathrm{~mW}$.

Según estos espectros podemos concluir que mientras el hueso presenta una banda intensa a $955 \mathrm{~cm}^{-1}$ asignable a la vibración P-O-P de la hidroxiapatita, componente mayoritario de los huesos, en la zona del pigmento aparecen bandas asignables a vibraciones de los enlaces $\mathrm{Fe}-\mathrm{O}$, en particular, propias de la fase hematita, aunque también podría haber otras fases menos ordenadas, y a vibraciones de los enlaces $\mathrm{Si}-\mathrm{O}$ y $\mathrm{Si}-\mathrm{O}-\mathrm{Al}$ correspondientes a alumino-silicatos amorfos. En cambio, las numerosas bandas de la tierra circundante podrían ser asignadas a diferentes compuestos inorgánicos, aunque entre ellos no se encuentran óxidos de hierro ni los mismos aluminosilicatos que en la zona del pigmento, por lo que ambos tienen composición diferente.
En conclusión, los resultados de las analíticas inducen a considerar que las marcas rojas sobre el soporte óseo corresponden, tal y como ya habían mostrado los análisis anteriores realizados

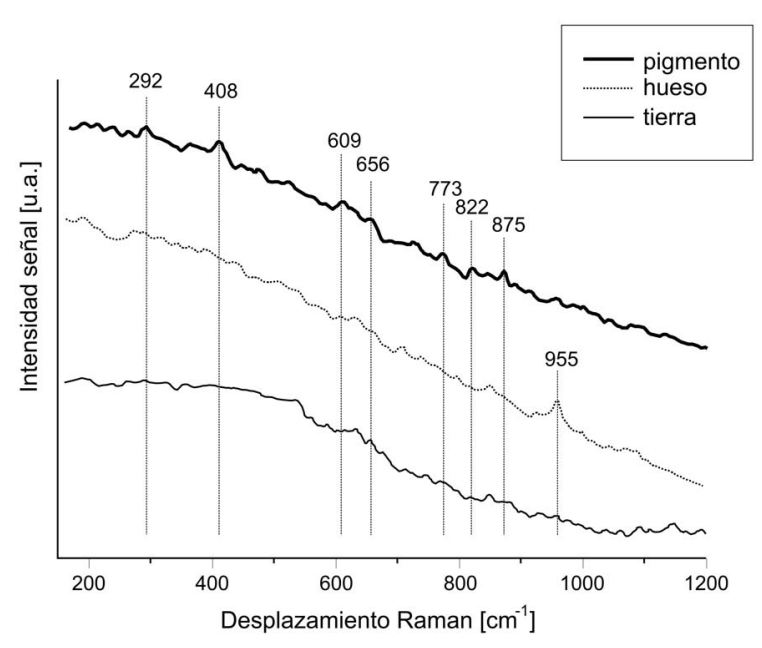

Fig. 11. Tumba 1 de la Illeta dels Banyets (El Campello, Alicante). Espectros Raman de zonas del cúbito izquierdo del esqueleto del individuo femenino con y sin pigmentación rojiza y del sedimento recogido durante la limpieza de los huesos. 
en la Universidad de La Laguna, a óxidos de hierro. En cambio, los análisis $X R D$ del sedimento indican únicamente la presencia de las fases cristalinas de la calcita $\left(\mathrm{CO}_{3} \mathrm{Ca}\right)$ y del cuarzo $\left(\mathrm{SiO}_{2}\right)$, lo que permite descartar que los óxidos ferrosos puedan proceder del entorno sedimentario en el que fue hallado el esqueleto.

\section{DISCUSIÓN}

Hace ya más de una década, G. Delibes (2000: 230) señalaba la posibilidad de que las coloraciones rojizas que mostraban algunos esqueletos argáricos constituyeran el residuo revelador de prácticas de embalsamamiento de algunos cadáveres. El teñido con fines exclusivamente ornamentales de prendas de vestir resultaba desaconsejable, a su juicio, por razones de índole sanitario relativas a la toxicidad del sulfuro de mercurio. En su momento manifestamos nuestros reparos a esta hipótesis. Al margen de la posible significación ritual y del contenido simbólico que el color rojo hubiera podido tener en las prácticas funerarias argáricas, el embadurnamiento de cadáveres post mortem no explicaba convenientemente la presencia de tinciones en algunos botones de perforación en $\mathrm{V}$ y en otros elementos de marfil que se supone estaban cosidos a los ropajes de los inhumados. En la mayoría de los casos estos concentran los residuos colorantes en su zona basal, la parte en contacto más estrecho con la tela desaparecida (López Padilla 2006).

Una década más tarde seguimos sin tener pruebas que corroboren de forma irrefutable la tinción de tejidos en época argárica, al menos empleando el cinabrio. De hecho, las pruebas aducidas en este sentido por los Siret -la supuesta cinta o diadema del cráneo femenino de la tumba 356 o las manchas observadas sobre las improntas de barro de la tumba 797- continúan siendo las más relevantes.

La inmensa mayoría de los fragmentos de tejido de época argárica conservados se encuentran impregnados de sales de cobre y sulfuros que impiden comprobar si originalmente alguno de ellos estaba teñido. En los contados casos en los que no se produjo su completa descomposición, como en la tumba 121 de Castellón Alto (Galera, Granada), de la información publicada no ha trascendido que ninguno presentara tinciones (Molina et al. 2003; Rodríguez-Ariza et al. 2004). Lo mismo ocurre con otros casos de similar cronología hallados en áreas colindantes del espacio argárico, como en la cueva $n .^{\circ} 9$ del Monte Bolón, en Elda (Alicante) (Soler et al. 2009).

El único tejido con tinciones analizado en la zona del que tengamos noticia es el lienzo de Cueva Sagrada, en Lorca (Murcia), asociado a un enterramiento excepcionalmente bien conservado datado en torno a 2300 cal ANE (Eiroa 2005: 170 ), en un horizonte cronológico inmediatamente anterior al desarrollo del grupo argárico. Desde un primer momento se mencionó una tonalidad ocre-anaranjada en algunos trozos que hacía pensar en el posible teñido de la tela (Ayala 1987: 11). Los análisis realizados a varias muestras de tejido ofrecieron indicios del empleo de Rubia tinctorum o rubia roja. La raíz de esta planta, de un color rojo intenso, convenientemente molida una vez seca, fue ampliamente utilizada en la antigüedad para preparar un colorante que se empleó sobre todo en la tinción de lanas y cueros. El mordiente usado en los lienzos de lino de Cueva Sagrada habría sido, siempre según el citado análisis, el alumbre o sulfato de aluminio (Alfaro 2005: 237). Desafortunadamente, no se incluyen en la publicación datos esenciales, como las gráficas correspondientes a la espectrografía de la muestra, pero parece claro que ni el cinabrio ni el óxido de hierro fueron empleados como material colorante, sino un tinte de origen vegetal.

En consecuencia, aunque nada invalida la posibilidad de que el sulfuro de mercurio se utilizara como tinte en el coloreado de paños en época argárica, por el momento sigue siendo una hipótesis a corroborar. Tampoco los contextos en los que se ha documentado cinabrio permiten precisar si éste procede realmente de la descomposición de ropajes o telas teñidas o si se aplicó al cadáver de algún otro modo. Al respecto los Siret traían frecuentemente a colación la franja que ceñía el cráneo de la tumba 356, argumentando que de no proceder de la descomposición de una cinta de tela teñida solo habría podido fijarse al hueso afeitando la cabellera de un modo que se les antojaba completamente insólito (Siret y Siret 1890: 201).

Llaman la atención algunas similitudes entre dos ejemplos en los que se ha constatado el sulfuro de mercurio. En la tumba 12 del Convento de Madres Mercedarias las coloraciones rojizas no solo se encontraban sobre los huesos, sino 
alrededor de todo el esqueleto e incluso por debajo de él. Ello muestra evidentes afinidades con la tumba 202 de El Argar donde el colorante empleado, según los Siret, también era el cinabrio. Ambas sepulturas guardan así mismo una gran semejanza con la tumba 62 de La Bastida, de la que sin embargo desconocemos la sustancia colorante empleada. Nada más puede concluirse en este sentido con respecto a las tumbas con presencia demostrada de cinabrio, pues en el caso del Cerro de la Virgen reportado por J. Carrasco Rus (1979) no ha trascendido información alguna sobre el contexto del hallazgo, y se desconoce si el colorante aparecía solo adherido a los huesos o si también formaba una especie de película sobre ellos.

Esto último, al parecer, se dio en pocos casos, siendo mucho más numerosas las referencias a manchas de colorante localizadas en partes puntuales de los huesos. Tanto en la tumba 2 de Los Tintes como en la tumba V de la Illeta dels Banyets $y$, especialmente, en el esqueleto femenino de la tumba I de este mismo yacimiento, puede fácilmente comprobarse que todas las zonas teñidas están cercanas a la epidermis: frente, pómulos, mandíbula, escápula, epífisis de tibias, fémures, radio-cúbitos y peronés. En cambio faltan, por lo general, en las partes de los huesos cubiertas por una mayor masa muscular.

El concienzudo análisis de la localización de las manchas rojizas del esqueleto de la mujer de la tumba I de la Illeta (Fig. 12) ha mostrado que éstas siguen fielmente este mismo patrón, todavía más clarificador si atendemos a la reconstrucción ideal de la disposición que pudo tener originalmente el cadáver, antes de que fuera reducido y desplazado en el interior de la tumba: más o menos flexionado y apoyado sobre un costado, predominantemente el derecho, tal y como parece constituir la norma general para los enterramientos femeninos argáricos (Schubart 2004; López Padilla et al. 2006; Aranda et al. 2008). Se puede observar que las manchas rojizas se concentran claramente en los hombros, codos, caderas, rodilla izquierda y tobillos y, lo que resulta a nuestro juicio bastante significativo, se han reconocido en la cara externa de las costillas izquierdas en una proporción de 4/1 con respecto a las aparecidas en la cara ventral o interna de las costillas derechas.

La localización de las tinciones reportadas en otros casos parece ajustarse a una disposición

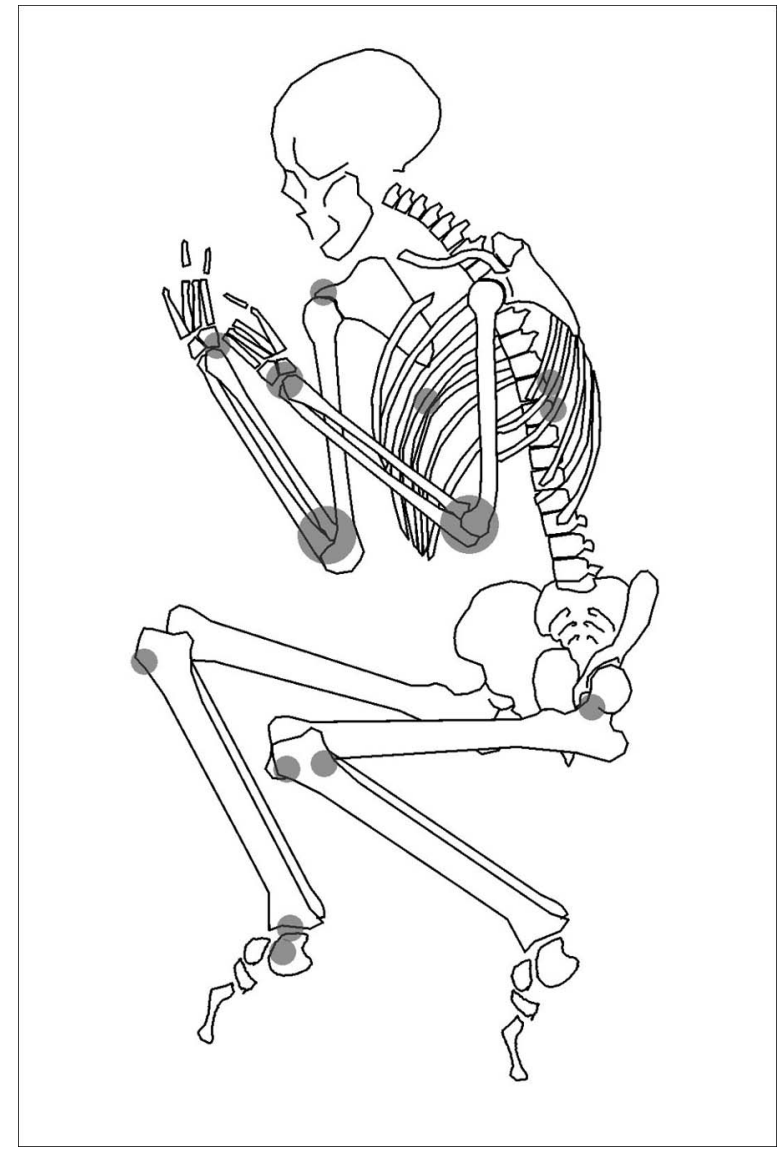

Fig. 12. Tumba 1 de la Illeta dels Banyets (El Campello, Alicante). Localización de zonas con coloraciones rojizas en el esqueleto del individuo femenino.

similar. Se mencionan manchas en el cráneo en las tumbas 5, 129, 202, 356 y 797 de El Argar -en su mayoría sobre la frente o en los pómulosasí como en las tumbas 2 de Los Tintes y 62 de La Bastida. La muestra tomada en la tumba 111 de Fuente Álamo también procedía de las proximidades del cráneo. La mujer de la tumba $\mathrm{V}$ de la Illeta presentaba manchas rojizas en la mandíbula. Furgús señalaba manchas en los brazos y antebrazos de un enterramiento femenino de San Antón sin precisar en qué parte concreta de los huesos se concentraban, pero sí se referencia expresamente que el cráneo de la mujer aparecía completamente 'embadurnado de negro'. Por último, sabemos que las manchas encarnadas halladas en la tumba 21 del Cerro de la Encina estaban sobre el borde exterior de la escápula izquierda del individuo femenino (Fig. 13). 


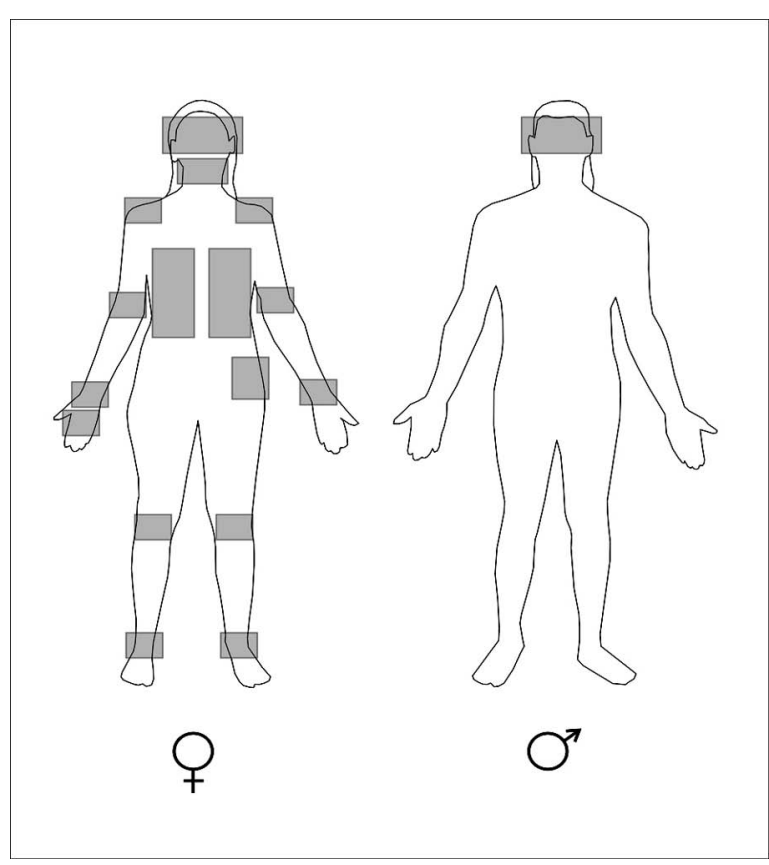

Fig. 13. Localización de coloraciones sobre huesos de esqueletos argáricos de hombres y mujeres, a partir de la documentación recopilada: El Argar (Antas, Almería), tumbas 5, 129, 356, 797; Fuente Alamo (Cuevas de Almanzora, Almería), tumba 111; Calle Los Tintes (Lorca, Murcia), tumba 2; Convento de las Madres Mercedarias (Lorca, Murcia), tumba 12; Cerro de la Encina (Monachil, Granada), tumba 21; Illeta dels Banyets (El Campe1lo, Alicante), tumbas I, V; San Antón (Orihuela, Alicante).

En la tumba I de la Illeta dels Banyets, las pigmentaciones tienden a concentrarse en las zonas del esqueleto de la mujer más próximas a la epidermis y faltan por completo en las principales superficies de inserción muscular de los huesos. Esto refuerza la hipótesis de que el ocre y el cinabrio hallados procedan de una transferencia a la superficie ósea de sustancias colorantes en contacto directo sobre la piel del cadáver. Lo que no permite es resolver si el colorante fue aplicado directamente sobre el cuerpo o si fue transferido a partir de los ropajes u otros elementos del atuendo de los difuntos.

Dada la variedad de formas en las que pudieron emplearse tanto el ocre como el cinabrio, el escenario que nos parece más probable en este momento contempla su posible uso tanto en el teñido de ropa y de otros complementos de la indumentaria argárica como también en el maquillaje corporal o la decoración pictórica de otros objetos de adorno. Todo ello al margen del sentido simbólico que la sociedad argárica pudiera haber atribuido al color rojo o a las propiedades de conservación o antisépticas que poseen ambas sustancias, especialmente el sulfuro de mercurio.

Tomando en consideración todos los datos reunidos hasta este momento, podría proponerse que el cinabrio detectado sobre los huesos -pero también en el sedimento que los rodea y sobre el que descansan- en sepulturas como la tumba 202 de El Argar o la tumba 12 del Convento de las Madres Mercedarias de Lorca, pudiera proceder realmente de la descomposición de los vestidos o sudarios teñidos de rojo con los que se vistió o cubrió originalmente al cadáver en el momento de su inhumación. Ello explicaría también las tinciones que mostraban las improntas de tejido observadas por los Siret en la tumba 797 de El Argar.

Sin nuevos datos que permitan corroborar la hipótesis del teñido de paños de lino o de tejidos de lana con óxidos férricos o con cinabrio, cabría también plantearse que el ocre que embadurna los huesos del enterramiento femenino de la tumba I de la Illeta dels Banyets y el aparecido en otras tumbas argáricas procediera de un maquillaje facial y/o corporal que se transfirió a los huesos tras la putrefacción del cadáver.

Por el momento no parece posible determinar si tal maquillaje pudo o no estar relacionado con tradiciones funerarias argáricas que persiguieran expresamente la conservación o embalsamamiento de los cadáveres, como proponía G. Delibes (2000). Comparado con el número total de sepulturas conocido para todo el territorio de El Argar, son muy pocas las que presentan esta particularidad, de manera que o contamos con un registro muy parcial a este respecto o bien no se trataría en ningún caso de una práctica generalizada.

El registro etnográfico permite suponer el empleo del hematite y otras materias colorantes para adornar el cuerpo con ocasión de ceremonias de carácter diverso, o incluso de forma cotidiana, habida cuenta de los beneficios del maquillaje corporal para la protección de la piel del ataque de parásitos o simplemente como desodorante o protector solar (Velo 1984). Una propuesta recurrente en la bibliografía, apoyada en no pocas referencias etnográficas, ha incidido en la asociación simbólica del color rojo con la sangre. $\mathrm{Su}$ reiterada presencia en contextos funerarios de 
diversas épocas y en muchas regiones del mundo se explica como un intento de recuperar para el cadáver un aspecto 'vital' mediante la aplicación o espolvoreado de sustancias colorantes que le confirieran un tono encarnado. Abundando en esta idea, el color rojo se relaciona con la idea de 'resurrección', de transformación y de tránsito, de 'renacimiento' en suma (Fitzsimmons 2009: 82).

Cabría preguntarse si el posible embadurnamiento de rojo de ciertos cadáveres en El Argar pudo haberse realizado durante el intervalo de 36 horas que transcurren hasta que desaparece el rigor mortis, durante las cuales debieron permanecer fuera de la sepultura. La posibilidad de que se expusiera el cadáver antes de su inhumación ya se había insinuado a partir de algunos indicios (Liesau 2001) y ha recibido un apoyo considerable a raíz del hallazgo de la tumba 121 de Castellón Alto (Molina et al. 2003).

Tampoco han faltado propuestas que enfatizan la vinculación del rojo con la feminidad, y en particular con las peculiaridades ligadas a las capacidades reproductoras de la mujer y su ciclo menstrual. Así se ha explicado la presencia bien constatada de pigmentos rojizos sobre figurillas femeninas prehistóricas, como las denominadas 'venus' de Grimaldi, Willendorf o Laussel (Petru 2006: 206).

Conviene atender a un segundo aspecto que parece evidenciar el registro: en la mayoría de los casos conocidos en el ámbito argárico el ocre o cinabrio en una sepultura se asocia con los restos de una mujer. No menos significativo es que en varios enterramientos dobles de un hombre y una mujer adultos sea el esqueleto de la mujer el que presenta las tinciones: tumba I de la Illeta, tumbas 356 y 797 de El Argar o la tumba 21 del Cerro de la Encina. En comparación con el conjunto del registro funerario argárico las 20 tumbas constatadas son un número muy reducido, al igual que el número de individuos enterrados asociados a sustancias colorantes (23). Además, no todos cuentan con una atribución de sexo probable o segura. Si consideramos globalmente los datos contenidos en la tabla 1 , vemos que 13 de las 14 mujeres presentan restos de colorantes, frente a solo 5 de los 9 hombres. Esta asociación preferente de las primeras con las tinciones se aproxima a la significación estadística (Test exacto de Fisher $\mathrm{p}=0.056$ ) si bien deberemos esperar todavía a incrementar el número de casos registrado (Fig. 14). Por ahora, la tumba 5 de El Argar es el único enterramiento individual masculino fehacientemente asociado a tinciones en su esqueleto, ya que el hombre inhumado en la tumba 2 de la calle de Los Tintes, en Lorca, apareció junto a una mujer. En ambos casos la materia roja se registró exclusivamente en el cráneo. En las tumbas 202 de El Argar y 30 de El Oficio -ambas tumbas dobles, con esqueletos de un hombre y una mujer- las manchas de color rojizo aparecían sobre los dos, sin precisar su localización.

En las tumbas 128 y 143 de El Oficio, las tinciones rojizas también parecen asociarse con esqueletos pertenecientes a individuos de sexo masculino (Kunter 1990: 40, 41). Posiblemente no sea casual que estas dos tumbas sean también, por ahora, las únicas del registro funerario argárico que aparentemente contradicen, desde la antropología física, la estrecha relación existente entre el punzón de metal y los enterramientos femeninos (Castro et al. 1993-94: 101). Si bien los criterios utilizados para la adscripción sexual del individuo de la tumba 143 pudieran considerarse no del todo concluyentes (Castro et al. 1993-94: 100), la conservación de una pelvis entre los restos esqueléticos de la tumba 128 no permite albergar dudas sobre la presencia de un hombre en la sepultura. Sin embargo, esta última

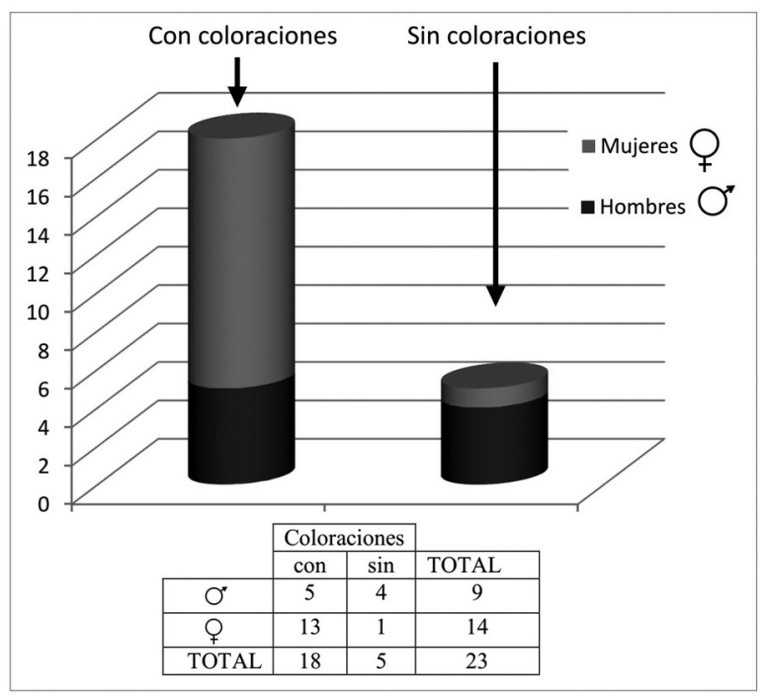

Fig. 14. Número de individuos masculinos y femeninos localizados en tumbas argáricas del sudeste de la Península Ibérica con residuos de sustancias colorantes y gráfico comparativo de la distribución del pigmento por sexos (cft. Tab. 1). 
tumba pudo haber sido reabierta o alterada con posterioridad a la inhumación del cadáver, pues Siret menciona expresamente que al esqueleto le faltaba el cráneo, y no se precisa qué partes esqueléticas tenían tinciones rojizas (Schubart y Ulreich 1991: 224). Creemos que si efectivamente eran hombres, la presencia de ocre o cinabrio en la sepultura podría estar reforzando la 'feminidad' ritual con la que se procedió a su enterramiento, ya de por sí manifiesta en la inclusión de un punzón de metal en el ajuar.

En conclusión, por ahora parece que los residuos colorantes en las tumbas argáricas se asocian de forma bastante marcada con los enterramientos femeninos. A nuestro juicio podría suponer otro dato revelador de la importancia de la mujer como elemento clave en las referencias parentales argáricas, ya propuesta en base a la secuencia de inhumación sucesiva detectada en la mayoría de los enterramientos dobles argáricos (Castro et al. 1993-94; Lull 1997-98). Aun teniendo bien presentes las ostensibles diferencias con respecto a la información disponible para cada caso, los datos recopilados en la tabla 1 muestran cómo la asociación del color rojo con los esqueletos de mujeres tiende claramente a vincularse con enterramientos individuales acompañados de ajuares de cierta relevancia -o incluso muy relevantes- o con inhumaciones dobles, en algún caso también con ajuares excepcionales, un aspecto sobre el que sin duda cabe continuar profundizando.

Restaría aún explicar el hecho de que algunos objetos -en su mayoría de marfil y teóricamente relacionados con la indumentaria- hallados en ciertas tumbas argáricas presenten tinciones y manchas rojizas cuando los esqueletos que los acompañan carecen aparentemente de ellas: caso de la tumba 247 de El Argar o de una de las cistas del yacimiento alicantino de Laderas del Castillo, en Callosa de Segura (López Padilla 2006). Algo que vemos repetirse en alguna sepultura documentada en la orla periférica argárica, como en la Morra del Quintanar (Munera, Albacete) (Fernández-Miranda et al. 1994: 260). Si tales pigmentaciones no proceden de la transferencia química de los colorantes empleados en el teñido de trajes o sudarios de los difuntos, cabría preguntarse si tal vez estamos ante los escasos residuos dejados por su ornamentación pictórica. Conviene recordar que, a propósito de los botones de perforación en ' $\mathrm{V}$ ' del Campaniforme cen- troeuropeo, R. J. Harrison (1980: 51) ya proponía que la pigmentación rojiza que mostraban muchos de ellos podía responder a un deseo de imitar el aspecto rúbeo del ámbar.

Creemos que este trabajo pone de relieve la extraordinaria importancia de la realización de este tipo de analíticas, siendo conscientes de que quedan sobre la mesa un buen número de cuestiones por resolver. Entre ellas figura determinar las fuentes de aprovisionamiento del cinabrio detectado en la tumba del Convento de las Madres Mercedarias de Lorca, para lo que será necesario contar con amplios y ambiciosos programas de muestreo. En nuestro caso nos han permitido corroborar el empleo del ocre y del cinabrio en varios contextos funerarios argáricos y también -y no menos importante- descartar su presencia en otros, como la tumba del yacimiento de Tabayá.

\section{AGRADECIMIENTOS}

A Jorge A. Soler Díaz, conservador de Prehistoria del MARQ de Alicante, a Concepción Navarro Poveda, directora del Museo Arqueológico Municipal de Novelda, y a Andrés Martínez Rodríguez, director del Museo Arqueológico de Lorca, por la colaboración y las facilidades prestadas para la toma de muestras de los restos óseos analizados.

\section{BIBLIOGRAFÍA}

Alfaro Giner, C. 2005: "Informe sobre los restos textiles, de cestería y de cuero procedentes de Cueva Sagrada I (Lorca, Murcia)". En J. J. Eiroa: El Cerro de la Virgen de la Salud (Lorca). Colección Documentos, Serie Arqueología 5, Servicio de Patrimonio Histórico. Murcia: 229- 246.

Aranda, G.; Molina, F.; Fernández, S.; Sánchez, M.; Al Oumaoui, I.; Jiménez, S. 2008: "El poblado y necrópolis argáricos del Cerro de la Encina (Monachil, Granada). Las campañas de excavación de 2003-2005". Cuadernos de Prehistoria y Arqueología de la Universidad de Granada 18: 219-264.

Arteaga, O. y Schubart, H. 1981: "Fuente Álamo: Campaña de 1979”. Noticiario Arqueológico Hispánico 11: 9-22.

Ayala Juan, M. M. 1987: "Enterramientos calcolíticos de la Sierra de La Tercia. Lorca. Murcia. Estudio preliminar". Anales de Prehistoria y Arqueología 3: 9-24. 
Berzosa del Campo, R. y Flores Díaz, M. 2005: "El conjunto funerario campaniforme del Vertedero de La Salmedina (Distrito Villa de Vallecas, Madrid)". En M. A. Rojo Guerra, R. Garrido Pena y I. García Martínez de Lagrán (coords.): El Campaniforme en la Península Ibérica y su contexto europeo. Universidad de Valladolid. Valladolid: 481-490.

Briceño Briceño, E. M. 2011: "La versatilidad de los colorantes minerales rojos en la Prehistoria reciente: Andalucía Occidental”. En J. Abellán, C. Lazarich y V. Castañeda (dir.): Homenaje al Profesor Antonio Caro Bellido I. Prehistoria y Protohistoria de Andalucía y Levante. Universidad de Cádiz: 39- 60.

Briceño, E. M.; Lazarich, M. y Feliu, M. J. 2009: "Polvo rojo para los difuntos. La utilización de ocres en la necrópolis del III y II milenios de Paraje de Monte Bajo. Alcalá de los Gazules. Cádiz”. I Congreso de Prehistoria de Andalucía. Memorial Luís Siret. La Tutela del Patrimonio Prehistórico. 22-25 de septiembre de 2010. Póster. http://www. memorialsiret.es/doc/posters/17-Necropolis-Monte-Bajo-Alcala-Gazules.jpg (consulta 4-VII-2011).

Bronk Ramsey, C. 2009: "Bayesian analysis of radiocarbon dates". Radiocarbon 51(1): 337-360.

Bueno Ramírez, P.; Barroso Bermejo, R. y De Balbín Behrmann, R. 2005: "Ritual campaniforme, ritual colectivo: La necrópolis de cuevas artificiales del Valle de Las Higueras, Huecas, Toledo". Trabajos de Prehistoria 62 (2): 67-90.

Buikstra, J. E. y Ubelaker, D. H. (eds). 1994: Standards for Data Collection from Human Skeletal Remains. Arkansas Archaeological Survey Research Series 44. Fayetteville.

Capel, J.; Huertas, F; Pozzuoli, A. y Linares, J. 2006: "Red ochre decorations in Spanish Neolithic ceramics: a mineralogical and technological study". Journal of Archaeological Science 33: 1157-1166.

Carrasco Rus, J. 1979: "Algunas cuestiones acerca de la Cultura Argárica en la provincia de Granada". $X V$ Congreso Nacional de Arqueología (Lugo 1977): 265-277. Zaragoza.

Castro Martínez, P. V.; Chapman, R. W.; Gili Suriñac, S.; Lull, V.; Micó, R., Rihuete Herrada, C.; Risch, R. y Sanahuja Yll, M. E. 1993-94: "Tiempos sociales de los contextos funerarios argáricos". Anales de Prehistoria y Arqueología 9-10 (1993): 77-105.

Delibes de Castro, G. 2000: "Cinabrio, huesos pintados en rojo y tumbas de ocre: ¿prácticas de embalsamamiento en la Prehistoria?". En M. Olcina y J. A. Soler (coords.): Scripta in honorem Enrique A. Llobregat Conesa, Instituto de Cultura Juan GilAlbert. Alicante: 223-236.

Domínguez-Bella, S. y Morata Céspedes, D. 1995: "Aplicación de las técnicas mineralógicas y petrológicas a la arqueometría. Estudio de materiales del Dolmen de Alberite (Villamartín, Cádiz)”. Zephyrus XLVIII: 129-142.
Eiroa García, J. J. 2005: El Cerro de la Virgen de la Salud (Lorca). Colección Documentos, Serie Arqueología 5, Servicio de Patrimonio Histórico. Murcia.

Fernández Miranda, M.; Fernández-Posse, M. D.; Gilman, A. y Martín, C. 1994: "La Edad del Bronce en La Mancha Oriental". La Edad del Bronce en Castilla-La Mancha. Actas del Simposio, 1990. Toledo: 243-277.

Fitzsimmons, J. L. 2009: Death and the Classic Maya Kings. University of Texas Press. Austin.

Furgús, J. 1905: "Tombes préhistoriques des environs d'Orihuela (Province d'Alicante, Espagne)". Annales de la Société d'Archéologie de Bruxelles, XIX, $3 .^{\circ}$ et $4 .^{\circ}$ liv.: $359-370$.

Furgús, J. 1937: Colleció de treballs del P. J. Furgús sobre Prehistoria Valenciana. Servei d'Investigació Prehistòrica, Treballs Solts 5. Valencia.

García Borja, P.; Domingo Sanz, I. y Roldán García, C. 2006: "Nuevos datos sobre el uso de materia colorante durante el Neolítico antiguo en las comarcas centrales valencianas". Saguntum 38: 49-60.

García Borja, P.; Domingo, I.; Roldán, C.; Verdasco, C.; Ferrero, J.; Jardón, P. y Bernabeu, J. 2004: "Aproximación al uso de la materia colorante en la Cova de l'Or". Recerques del Museu d'Alcoi 13: $35-52$.

García Sánchez, M. 1963: "El poblado argárico del Cerro del Culantrillo, en Gorafe (Granada)". Archivo de Prehistoria Levantina X: 69-96.

Harrison, R. J. 1980: The Beaker Folk. Copper Age archaeology in Western Europe. Thames and Hudson. London.

Hernández Pérez, M. S. 1990: "Un enterramiento argárico en Alicante". Homenaje a Jerónimo Molina. Academia Alfonso X El Sabio. Murcia: 87-94.

Hernández Pérez, M. S. y López Padilla, J. A. 2010: "La muerte en el Argar alicantino. El Tabaià como paradigma”. En A. Pérez y B. Soler (eds.): Restos de Vida, restos de muerte. La muerte en la Prehistoria. Diputación Provincial de Valencia. Valencia: 221-228.

Hernández Pérez, M. S. y Simón García, J. L. 1994: "La Edad del Bronce en el Corredor de Almansa (Albacete). Bases para su estudio". La Edad del Bronce en Castilla-La Mancha. Actas del Simposio, 1990. Toledo: 201-242.

Hunt Ortiz, M. A. y Hurtado Pérez, V. M. 2009: "Pigmentos de sulfuro de mercurio - cinabrio- en contextos funerarios de época calcolítica en el sur de la Península Ibérica: investigaciones sobre el uso, depósitos minerales explotados y redes de distribución a través de la caracterización composicional e isotópica". VIII Congreso Ibérico de Arqueometría (Teruel 2009): 123-132. http://www.segeda. net/8cia/pdf/06_3_Pigmentos_Hunt.pdf (consulta 17-VI-2011). 
Jacques, V. 1890: "Etnología”. En E. Siret y L. Siret: Las Primeras Edades del Metal en la Península Ibérica. Barcelona: 335-448.

Jover Maestre, F. J. y López Padilla, J. A. 1997: Arqueología de la muerte. Prácticas funerarias en los límites de El Argar. Universidad de Alicante. Alicante.

Juan Tresserras, J. J. 2004: "Fuente Álamo (Almería): análisis de los contenidos de recipientes cerámicos, sedimentos y colorantes procedentes de tumbas argáricas". Madrider Mitteilungen 45: 132-138.

Kunter, M. 1990: Menschliche Skelettreste aus Siedlungen der El Argar-Kultur. Madrider Beitrage 18. Philipp von Zabern. Mainz.

Kunter, M. 2000: "Los restos de esqueletos humanos hallados en Fuente Álamo durante las campañas de 1985, 1988 y 1991”. En H. Schubart, V. Pingel y O. Arteaga: Fuente Álamo. Las excavaciones arqueológicas 1977-1991 en el poblado de la Edad del Bronce. Junta de Andalucía. Sevilla: 265-282.

Kunter, M. 2004: "Die menschlichen Skelettreste aus den Grabungskampagnen 1996 und 1999 in Fuente Álamo". Madrider Mitteilungen 45: 88-96.

Liesau von Lettow-Vorbeck, C. 2001: "Fuente Álamo: evidencias de huesos humanos digeridos". En J. A. Sánchez Sánchez (ed.): Sistematización metodológica en Paleopatología. Actas del V Congreso $\mathrm{Na}$ cional (Alcalá la Real 1999). Asociación Española de Paleopatología. (CD-Rom): 65-71.

López Padilla, J. A. 2006: "Distribución territorial y consumo de botones de perforación en ' $\mathrm{V}$ ' en el ámbito argárico". Trabajos de Prehistoria 63 (2): 93-116.

López Padilla, J. A.; Belmonte Mas, D. y Miguel Ibáñez, M. P. de 2006: "Los enterramientos de la Illeta dels Banyets de El Campello. Prácticas funerarias en la frontera oriental de El Argar”. En J. A. Soler Díaz (ed.): La ocupación prehistórica de la Illeta dels Banyets (El Campello, Alicante). MARQ, Serie Mayor 5. Diputación de Alicante. Alicante: 119-171.

Lull, V. 1997-98: "El Argar: La muerte en casa". Anales de Prehistoria y Arqueología 13-14: 65-80.

Martin Gil, J.; Martin Gil, F.; Delibes de Castro, G.; Zapatero, P. y Sarabia, F. J. 1994: "Neolítico. Uso del Cinabrio". Investigación y Ciencia 219: 29-30.

Martínez Navarrete, M. I. 1984: “El comienzo de la metalurgia en la provincia de Madrid: la Cueva y el Cerro de Juan Barbero (Tielmes, Madrid)". Trabajos de Prehistoria 41: 17-89.

Martínez Rodríguez, A. y Ponce García, J. 2002a: "Excavación arqueológica de urgencia en el subsuelo de la antigua Iglesia del convento de las Madres Mercedarias (C/ Zapatería-C/ Cava, Lorca)". Memorias de Arqueología 10, 1995: 90-137.

Martínez Rodríguez, A. y Ponce García J. 2002b: “Segunda intervención arqueológica en la Plaza Juan Moreno n. ${ }^{\circ} 8$, confluencia con la calle Los Tintes (Lorca)". Memorias de Arqueología 10, 1995: 149-160.
Martínez Rodríguez, A.; Ponce García, J. y Ayala Juan, M. M. 1996: Las Prácticas funerarias de la Cultura Argárica en Lorca, Murcia. Caja de Ahorros de Murcia y Ayuntamiento de Lorca. Lorca.

Martínez Santa-Olalla, J.; Sáez Martín, B.; Posac, C.; Sopranis, J. A. y Val, E. del 1947: Excavaciones en la ciudad del Bronce Mediterráneo II, de La Bastida de Totana. Ministerio de Educación Nacional, Informes y Memorias 16. Madrid.

Molina González, F.; Rodríguez-Ariza, M. O.; Jiménez Brobeil, S. A y Botella López, M. C. 2003: "La sepultura 121 del yacimiento argárico de El Castellón Alto (Galera, Granada)". Trabajos de Prehistoria 60 (1): 153-158.

Navarro Mederos, J. F. 1982: "Materiales para el estudio de la Edad del Bronce en el Valle Medio del Vinalopó (Alicante)". Lucentum II: 19-68.

Petru, S. 2006: "Red, black or white? The dawn of colour symbolism". Documenta Praehistorica 33: 203-208. http://arheologija.ff.uni-lj.si/documenta/ pdf33/petru33.pdf (consulta 23-II-2011).

Pingel, V.; Schubart, H.; Arteaga, O.; Roos A. M. y Kunst, M. 2003: "Excavaciones arqueológicas en la ladera sur de Fuente Álamo. Campaña de 1999". SPAL, 12: 179- 229.

Ríos, P. y Liesau, C. 2011: "Elementos de adorno, simbólicos y colorantes en contextos funerarios y singulares". En C. Blasco, C. Liesau y P. Ríos (eds.): Yacimientos calcolíticos con campaniforme de la Región de Madrid: nuevos estudios. Patrimonio Arqueológico de Madrid 6: 357-370.

Reimer, P. J.; Baillie, M. G. L.; Bard, E.; Bayliss, A.; Beck, J. W.; Blackwell, P. G.; Bronk Ramsey, C.; Buck, C. E.; Burr, G. S.; Edwards, R. L.; Friedrich, M.; Grootes, P. M.; Guilderson, T. P.; Hajdas, I.; Heaton, T. J.; Hogg, A. G.; Hughen, K. A.; Kaiser, K. F.; Kromer, B.; McCormac, F. G.; Manning, S. W.; Reimer, R. W.; Richards, D. A.; Southon, J. R.; Talamo, S.; Turney, C. S. M.; van der Plicht, J. y Weyhenmeyer, C. E. 2009: "IntCal09 and Marine09 radiocarbon age calibration curves, 0-50,000 years cal BP". Radiocarbon 51(4): 1111-1150.

Rodríguez-Ariza, M. O.; Molina González, F.; Botella López, M. C.; Jiménez Brobeil, S. A. y Alemán Aguilera, I. 2004: "Les restes parcialment momificades de la sepultura 121 del jaciment argàric de Castellón Alto (Galera, Granada)". Cota Zero 19: 13-15.

Rovira Llorens, S. y Sanz Nájera, M. 1984: "Apéndice 2. Análisis de laboratorio de algunos materiales de la Cueva de Juan Barbero". En M. I. Martínez Navarrete: "El comienzo de la metalurgia en la provincia de Madrid: la Cueva y el Cerro de Juan Barbero (Tielmes, Madrid)". Trabajos de Prehistoria 41: 94-104.

Schubart, H. 2004: "Das reiche Grab einer jungen Frau aus dem El Argar-zeitlichen Fuente Álamo". Madrider Mitteilungen 45: 57-79. 
Schubart, H. y Ulreich H. 1991: Die Funde der Südostspanischen Bronzezeit aus der Sammlung Siret. Madrider Beiträge 17. Philipp von Zabern. Mainz am Rhein.

Schubart H.; Pingel, V.; Kunter, M.; Liesau von Lettow-Vorbeck, C.; Pozo, M.; Medina, J. A.; Casa, J.; Tresserras Juan, J. y Hägg, I. 2004: "Studien zum Grab 111 der Nekropole von Fuente Álamo (Almería)". Madrider Mitteilungen 45: 57-146.

Siret, E. 1905: "Note sur la communication du R.P. Furgús relative á des tombes préhistoriques a Orihuela". Annales de la Société d'Archéologie de Bruxelles XIX: 371-380.

Siret, E. y Siret, L. 1890: Las Primeras Edades del Metal en la Península Ibérica. Barcelona.

Soler Díaz, J. A. 2006: La ocupación prehistórica de la Illeta dels Banyets (El Campello, Alicante). MARQ. Serie Mayor 5, Diputación de Alicante. Alicante.
Soler Díaz, J. A.; López Padilla, J. A.; Roca de Togores, C.; Benito Iborra, M. y Botella López, M. 2009: "Sepultura infantil de la Edad del Bronce de Monte Bolón”. Elda, arqueología y museo. MARQ. Diputación de Alicante: 38-59.

Velo, J. 1984: "Ochre as medicine: A suggestion for the interpretation of the archeological record". $\mathrm{Cu}$ rrent Anthropology 25 (5): 674.

Zilhão, J.; Angelucci, D. E.; Badal, E.; d'Errico, F.; Daniel, F.; Dayet, L.; Douka, K.; Higham, T. F. G.; Martínez-Sánchez, M. J.; Montes-Bernárdez, R.; Murcia-Mascarós, S.; Pérez-Sirvent, C., RoldánGarcía, C.; Vanhaerenk, M.; Villaverde, V.; Wood, R. y Zapata, J, 2010: "Symbolic use of marine shells and mineral pigments by Iberian Neandertals". Proceedings of the National Academy of Sciences 107 (3): 1023-1028 http://www.pnas.org/ content/early/2010/01/06/0914088107.full. pdf + html (consulta 12-VII-2011). 